\title{
Polycomb genes interact with the tumor suppressor genes hippo and warts in the maintenance of Drosophila sensory neuron dendrites
}

\author{
Jay Z. Parrish, Kazuo Emoto, ${ }^{1}$ Lily Yeh Jan, and Yuh Nung Jan ${ }^{2}$ \\ Howard Hughes Medical Institute, Department of Physiology, and Department of Biochemistry and Biophysics, \\ University of California at San Francisco, San Francisco, California 94143, USA
}

\begin{abstract}
Dendritic fields are important determinants of neuronal function. However, how neurons establish and then maintain their dendritic fields is not well understood. Here we show that Polycomb group (PcG) genes are required for maintenance of complete and nonoverlapping dendritic coverage of the larval body wall by Drosophila class IV dendrite arborization (da) neurons. In esc, Su(z)12, or Pc mutants, dendritic fields are established normally, but class IV neurons display a gradual loss of dendritic coverage, while axons remain normal in appearance, demonstrating that PcG genes are specifically required for dendrite maintenance. Both multiprotein Polycomb repressor complexes (PRCs) involved in transcriptional silencing are implicated in regulation of dendrite arborization in class IV da neurons, likely through regulation of homeobox (Hox) transcription factors. We further show genetic interactions and association between PcG proteins and the tumor suppressor kinase Warts (Wts), providing evidence for their cooperation in multiple developmental processes including dendrite maintenance.
\end{abstract}

[Keywords: Drosophila; neuron; dendrite; Polycomb; homeobox; tumor suppressor]

Supplemental material is available at http://www.genesdev.org.

Received November 20, 2006; revised version accepted February 26, 2007.

Dendrite arborization patterns are important for neuronal function and proper wiring of neuronal circuitry. Moreover, sensory perception in some cases depends on complete and nonredundant coverage of the receptive field by dendrites of functionally related neurons, a phenomenon known as tiling. For example, many types of neurons tile the mammalian retina, most likely to ensure efficient and unambiguous representation of the visual field. At least 11 distinct physiological classes of rabbit retinal ganglion cells (RGCs) cover their receptive field nonredundantly by avoiding overlap between dendrites of a single neuron as well as between dendrites of the same type of neurons, whereas dendrites of different types of neurons freely cross one another (Wassle et al. 1978, 1983; Rockhill et al. 2002). Similarly, >20 classes of amacrine cells in the rabbit retina can be distinguished on the basis of dendrite morphology, and many of these classes of amacrine cells appear to tile the retina. Sensory neurons in Manduca, Drosophila, and the leech Hirudu medicinalis also exhibit tiling, suggesting that

\footnotetext{
${ }^{1}$ Present address: Neural Morphology Laboratory, National Institute of Genetics, Yata 1111, Mishima, Shizuoka 411-8540, Japan.

${ }^{2}$ Corresponding author.

E-MAIL ynjan@itsa.ucsf.edu; FAX (415) 476-5774.

Article is online at http://www.genesdev.org/cgi/doi/10.1101/gad.1514507.
}

tiling may be a general mechanism to organize dendritic fields (Grueber et al. 2002; Grueber and Jan 2004).

Once neurons tile their receptive field and achieve complete coverage during development, the tiling is maintained even as the territory changes; for example, as the animal grows in size. Whereas like-repels-like homotypic repulsion is one mechanism important for the establishment of receptive fields (Grueber et al. 2003b), how tiling is maintained after the establishment of the dendritic field is not well understood. Underscoring the potential physiological significance of the maintenance of dendritic fields, dendrites of layer III cortical neurons develop normally but then degenerate postnatally in Down syndrome patients (Benavides-Piccione et al. 2004). Furthermore, defects in dendrite development are the strongest correlate with mental retardation, and dendrite maintenance defects may underlie a variety of developmental disorders (Kaufmann and Moser 2000).

The Drosophila peripheral nervous system (PNS) contains identifiable neurons with cell type-specific dendritic morphologies, including the dendrite arborization (da) neurons (Bodmer and Jan 1987). Dendrites of class IV da neurons tile the body wall and are amenable to genetic analyses of dendrite field formation and maintenance (Grueber et al. 2002, 2003b; Emoto et al. 2004). 
Class IV neurons begin to elaborate their dendrites during embryogenesis, and they achieve complete but nonredundant coverage of the body wall early in larval development. Embryonic ablation of class IV neurons prior to establishment of dendritic tiling causes an invasion of the vacated dendritic territories by neighboring class IV neurons (Grueber et al. 2003b; Sugimura et al. 2003). Conversely, duplication of class IV neurons results in a partitioning of the receptive field. Therefore, the dendritic fields of class IV neurons are established by homotypic repulsion.

After dendritic territories are established by like-repels-like repulsion, dendritic arbors of class IV neurons continue to grow in proportion to the size of the growing larva and maintain the tiling of the body wall. Ablation of larval class IV neurons after dendritic fields are established results in only limited invasion of the unoccupied space by terminal dendrites of neighboring class IV neurons (Grueber et al. 2003b). It thus appears that tiling in the growing larva is not maintained simply by continued dendritic growth limited via homotypic repulsion. Rather, additional mechanisms are likely at work to ensure that the complete, nonredundant coverage of the receptive field by class IV dendrites is maintained. Some of the first insight into the mechanisms for dendrite maintenance came from recent findings that the NDR kinase Warts (Wts) regulates dendrite maintenance in Drosophila class IV neurons (Emoto et al. 2006). Wts is phosphorylated by the Ste-20 kinase Hippo (Hpo), and Hpo plays important roles in both the establishment and maintenance of dendritic tiling. Therefore, a better understanding of the mechanisms for dendrite maintenance may be facilitated by the identification of gene products acting in the same pathway as Hpo and Wts.

From a comprehensive screen for transcription factors that regulate dendrite morphogenesis in Drosophila class I da neurons, several Polycomb group (PcG) genes were identified (Parrish et al. 2006), providing the first indication that PcG genes might be important regulators of dendrite development. However, to what extent PcG genes regulate neuronal morphology is unknown. PcG genes are evolutionarily conserved regulators of gene expression that act by establishing and maintaining repression of developmentally regulated genes. Biochemically and functionally, PcG genes can be separated into two multiprotein complexes referred to as Polycomb repressor complex 1 (PRC1) and PRC2 (Lund and van Lohuizen 2004). Although many details of the mechanisms of PcGmediated silencing of gene expression remain to be elucidated, PRC2 appears to function by methylating Lys 9 and/or Lys 27 of histone $\mathrm{H} 3$ that is associated with the Polycomb response element (PRE) of target genes, and PRC1, possibly through the combined action of histone ubiquitination and chromatin compaction, facilitates silencing (Lund and van Lohuizen 2004; Ringrose and Paro 2004). The methyltransferase activity of PRC2 that is essential for proper Polycomb-mediated silencing requires the PRC2 core components such as the methyltransferase Enhancer of zeste [E(z)], the WD-40-contain- ing protein extra sex combs (ESC), and the zinc finger protein Suppressor of zeste 12 [Su(z)12] (Jones et al. 1998; Ng et al. 2000; Tie et al. 2001; Cao et al. 2002; Czermin et al. 2002; Muller et al. 2002). The PRC1 protein complex is composed of Polycomb (Pc), Posterior Sex Combs (Psc), and Polyhomeotic (pho), as well as several other proteins including components of the core transcriptional machinery (Saurin et al. 2001). Although the targets of PcG genes remain largely unknown, homeobox (Hox) transcription factors are major targets of regulation by PcG genes. PcG genes play a well-established role in regulating the spatial and temporal pattern of Hox gene expression that is important in specifying segmental identity (Struhl 1983; Simon et al. 1992, 1993).

Here we report that PcG genes function cell-autonomously to regulate the arborization of Drosophila class IV da neuron dendrites. Mutations in PcG genes cause mounting defects in the dendrite coverage of class IV dendrites over time, but cause no obvious defects in axon terminal morphology, suggesting that PcG genes specifically function to maintain dendritic arbors in class IV neurons. PcG genes are required for post-mitotic downregulation of the Bithorax Complex $(\mathrm{BX}-\mathrm{C})$ Hox proteins Ubx, AbdA, and AbdB specifically in larval class IV da neurons. Moreover, PcG mutations genetically interact with mutations in components of the $\mathrm{Hpo} / \mathrm{Wts}$ signaling pathway to affect dendrite development, and Wts can physically associate with the PcG protein ESC. These findings suggest that the PcG gene products function together with the $\mathrm{Hpo} / \mathrm{Wts}$ signaling pathway to promote dendritic maintenance in class IV da neurons through a mechanism that likely involves post-mitotic repression of Hox gene expression.

\section{Results}

PcG genes autonomously regulate dendrite arborization in a particular class of sensory neurons

From an RNA interference (RNAi) screen for transcriptional regulators of sensory neuron dendrite development in Drosophila, we previously identified multiple PcG genes. PcG-mediated transcriptional silencing requires the activity of two multiprotein complexes, PRC1 and PRC2. To test whether these complexes act in da neurons to regulate dendrite development, we used MARCM (mosaic analysis with a repressible cell marker) (Lee and Luo 2001) to generate single-cell clones homozygous for null mutations in Pc (a component of PRC1), $E(z)$, esc, or $\operatorname{Su}(z) 12$ (each a component of PRC2) in a heterozygous background and analyzed the effects on dendrite development. On its own, heterozygosity for null alleles of $E(z)$, esc, $\operatorname{Su}(z) 12$, or Pc was not sufficient to cause dendrite defects (Fig. 1J). However, $E(z)^{63}$ homozygous mutant class IV neuron clones in third instar larvae showed a range of defects (Fig. 1B). In severe cases, $E(z)^{63}$ mutant class IV neurons cover only a small portion of the receptive field normally covered by class IV neurons, and had more than a fivefold reduction in dendrite branchpoints and a threefold reduction in total den- 
Parrish et al.
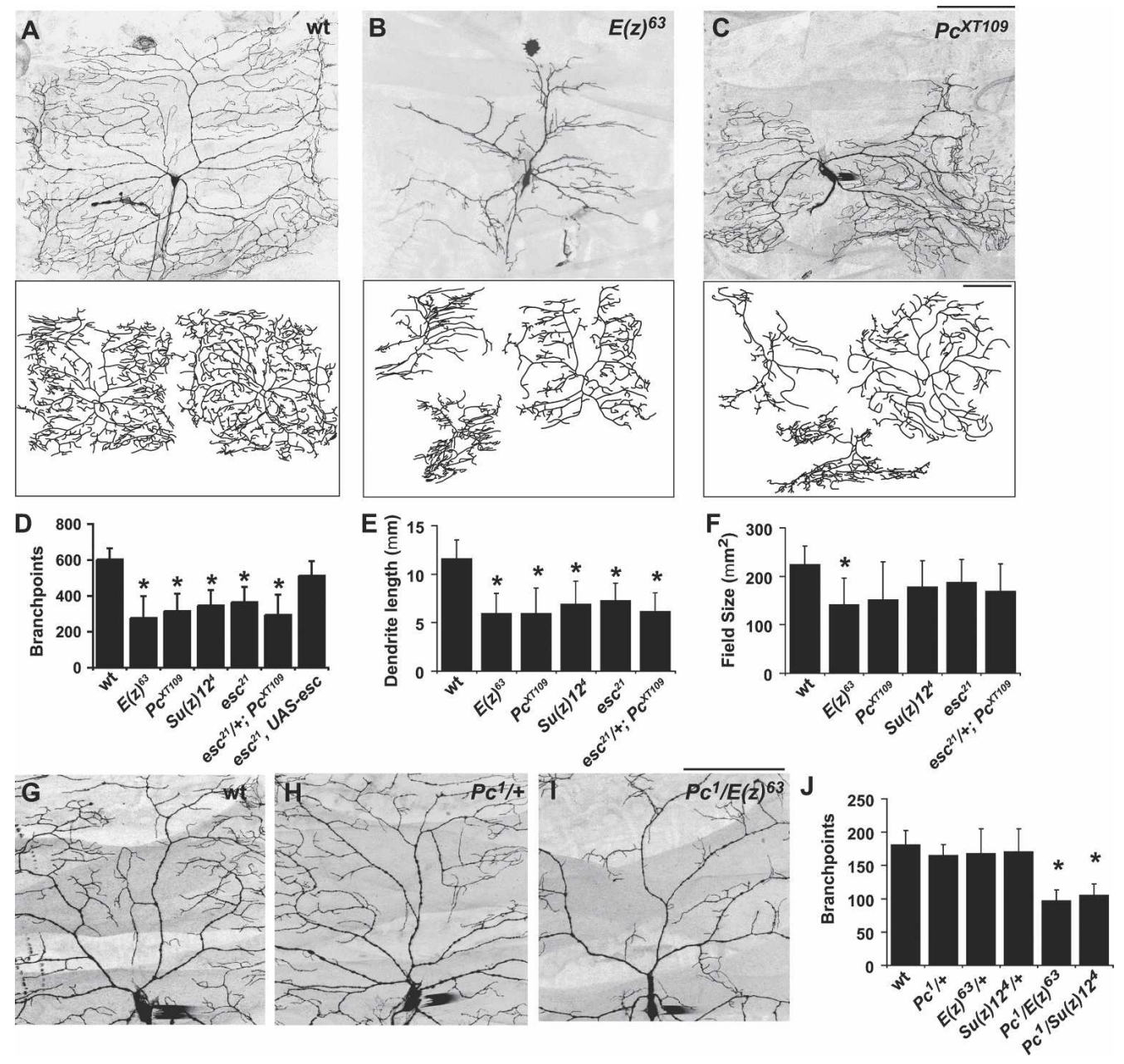

Figure 1. PcG genes are required cell-autonomously for proper dendrite development of class IV da neurons. (A) MARCM clone of the class IV neuron ddaC. The range of branching patterns observed in Frt2A clones are depicted as camera lucida of additional representative clones below the image. Clone genotype: w, Gal4 ${ }^{\text {elav }}$, UAS-mCD8::GFP/+; Frt2A/Frt2A. Dorsal is up and anterior is left in this and all subsequent images. Bar, $50 \mu \mathrm{m}$. $(B) E(z)^{-/-}$class IV ddaC clones fail to properly cover the receptive field and show a significant reduction in dendritic branching. The phenotypic range of $E(z)^{-1-} \mathrm{ddaC}$ clones is represented as camera lucida of three independent clones below the image. Clone genotype: w, Gal4 ${ }^{\text {elav }}$, UAS-mCD8::GFP/+; E $(z)^{63}$ Frt2A/E $(z)^{63}$ Frt2A. (C) Pc ${ }^{-/-}$class IV ddaC are also defective in both dendrite arborization and dendritic branching. Camera lucida represent the phenotypic range of $P c^{-/-} \mathrm{ddaC}$ mutant clones of the genotype w, Gal4elav, UAS-mCD8::GFP/+; Pc XT109 Frt2A/PC ${ }^{X T 109}$ Frt2A. (D) Average number of total dendrite branches in wild-type $(\mathrm{wt}), E(z)^{63}, P c^{X T 109}, S u(z)^{4}, e s c^{21}$, or $e s c^{21} /+; P c^{X T 109}$ ddaC MARCM clones. Error bars represent one standard deviation and asterisks $\left(^{\star}\right)$ denote $p<0.05$ relative to wild-type controls. $(E)$ Total dendritic length of wild-type, $E(z)^{63}, P c^{X T 109}, S u(z)^{4}, e s c^{21}$, or $^{21}$ $e s c^{21} /+; P c^{X T 109} \mathrm{ddaC}$ MARCM clones. $(F)$ Area of dendritic field covered by wild-type, $E(z)^{63}, P c^{X T 109}, S_{u}(z)^{4}, e s c^{21}$, or $_{e s c^{21} /+;} \mathrm{Pc}^{X T 109}$ ddaC MARCM clones. $(G-I)$ Live image of third instar class IV ddaC neuron visualized using pickpocket-Gal4, UAS-mCD8::GFP in wild-type $(G), P c^{1} /+$ heterozygous $(H)$, or $P c^{1} / E(z)^{63}$ trans-heterozygous $(I)$ larva. Anterior is left, and dorsal is up. Bar, $50 \mu m$. $(J)$ Quantification of dendrite branchpoints normalized to total dendritic length in ddaC of wild-type, $P c^{1} /+, E(z)^{63} /+, S_{u}(z) 12^{4} /+, P c^{1} /$ $E(z)^{63}$, or $P c^{1} / \mathrm{Su}(z) 12^{4}$ larvae. Error bars represent one standard deviation and asterisks $\left({ }^{\star}\right)$ denote $p<0.05$ relative to wild-type controls.

drite length. Qualitatively similar defects were apparent in nearly all $E(z)^{63}$ mutant clones, and clones representing the phenotypic range are depicted as camera lucida in Figure 1B. On average, $E(z)^{63}$ mutant class IV neurons displayed a $>50 \%$ reduction in dendrite branch points and dendrite length $(p<0.05)$ (Fig. 1D,E).

Terminal dendrite branches were more severely affected than major dendritic branches in $E(z)^{63}$ mutants, and as a result, the receptive field of mutant clones covered only $75 \%$ of the space occupied by wild-type con- trols in third instar larvae (Fig. 1F). Similar to wild-type controls, shortly following ablation of class IV neurons in $E(z)$ heterozygous embryos, neighboring class IV neurons expand their dendritic field to fill the unoccupied space (data not shown). However, even in $E(z)^{63}$ clones that occupied $<50 \%$ of the normal dendritic territory, HRP staining of sensory neurons revealed that neighboring $E(z)^{63}$ heterozygous class IV neurons showed very little invasion into the unoccupied territory at this late stage of larval development (data not shown), suggesting 
that the dendrite defects might have arisen after the dendritic fields of class IV neurons were specified.

$P c^{X T 109}, \operatorname{Su}(z) 12^{1}, \operatorname{Su}(z) 12^{4}$, or esc ${ }^{21}$ mutant class IV MARCM clones showed dendritic defects similar to $E(z)^{63}$ mutant clones (Fig. 1C-F; data not shown). Mutation of $P c, \operatorname{Su}(z) 12$, or esc each caused an $\sim 50 \%$ reduction in the number of dendrite branchpoints and overall dendritic length of class IV dendrites when compared with wild-type controls (Fig. 1D,E). Furthermore, $P c^{X T 109}$, $\mathrm{Su}(z) 12^{4}$, or esc ${ }^{21}$ mutant class IV neurons had deficits in dendritic coverage that were comparable to $E(z)^{63} \mathrm{mu}$ tant clones (Fig. 1F). To address the possibility that protein perdurance was masking the severity of the mutant phenotypes, we generated homozygous $P c^{X T 109}$ or $E(z)^{63}$ mutant clones that were additionally heterozygous for a null allele of esc $\left(e s c^{21}\right)$. The dendrite defects we observed in these clones were indistinguishable from the defects observed with $P c^{X T 109}$ or $E(z)^{63}$ mutations alone (Fig. 1D-F; data not shown). Finally, we tested whether expression of UAS-esc was sufficient to rescue the dendrite defects we observed in $\operatorname{esc}^{21}$ mutant MARCM clones and found that the dendritic branching in $\operatorname{esc}^{21}$ mutant clones expressing UAS-esc was indistinguishable from wild-type controls (Fig. 1D). Therefore, PcG genes, including components of PRC1 and PRC2, likely function cell-autonomously to ensure proper development of class IV dendrites.

To determine whether the role of PcG genes in regulating dendrite development is neuronal type-specific, we analyzed $E(z)^{63}, \operatorname{Pc}^{X T 109}, \operatorname{Su}(z) 12^{4}$, or $\operatorname{esc}^{21}$ mutant clones in other classes of sensory neurons, including external sensory (es); chordotonal (ch); bipolar dendritic (bd); and class I, II, and III da neurons. For each class examined, mutation of $P c$, esc, Su(z)12, or $E(z)$ had no significant effect on dendrite morphology (Supplementary Fig. S1; data not shown). Therefore, the PcG RNAi phenotypes we observed in class I da neurons likely reflect nonautonomous functions of PcG genes (Parrish et al. 2006). Because PcG genes appear to play a more critical role in autonomously regulating development of class IV neurons, we focused the remainder of our studies on understanding the function of PcG genes in regulating class IV dendrite development.

\section{Genes encoding components of PRC1 and PRC2 genetically interact to regulate dendrite development}

We reasoned that if PRC1 and PRC2 genes function together to regulate dendrite development, trans-heterozygous combinations of mutations in PRC1 and PRC2 genes might display synthetic phenotypes. To examine this possibility, we first tested whether mutants heterozygous for strong loss-of-function alleles of $E(z), P c$, or $\mathrm{Su}(z) 12$ had any defects in class IV dendrite development. On its own, heterozygosity for $E(z)^{63}, P c^{3}$, or $\mathrm{Su}(z) 12^{4}$ had no effect on dendrite branch number or dendrite length (Fig. 1G-J; data not shown). Trans-heterozygous combinations of PRC1 and PRC2 mutants, such as $P C^{3} / E(z)^{63}$, showed synthetic phenotypes that were qualitatively similar to the dendrite phenotypes we observed in $E(z)^{63}, P c^{X T 109}, \operatorname{Su}(z) 12^{4}$, or esc ${ }^{21}$ mutant MARCM clones, with a significant reduction in the number of dendritic branchpoints (Fig. 1I,J). Likewise, trans-heterozygous combinations of mutant alleles of genes for different PRC2 proteins, such as $E(z)^{63} /$ $\operatorname{Su}(z) 12^{4}$, also caused synthetic dendritic defects (Fig. 1J). Therefore, consistent with a shared function in regulating dendrite development, PRC1 and PRC2 genes display dosage-sensitive genetic interactions in class IV neurons.

\section{PcG mutants display a progressive loss of dendrites}

The dendrite defects we observed in $E(z)^{63}, P c^{X T 109}$, $\operatorname{Su}(z) 12^{4}$, or $\operatorname{esc}^{21}$ mutant clones could be the result of defects in dendrite growth and/or branching during development, or a defect in maintenance of dendrites. To distinguish between these possibilities, we first took advantage of the fact that $e s c^{21}$-null mutants can survive through larval stages and often into adulthood, allowing for analysis of dendrite morphology throughout larval development. In wild-type larvae or larvae that are heterozygous for a null allele of esc, class IV dendrites completely and nonredundantly tile the body wall by $48 \mathrm{~h}$ after egg laying (AEL). In larvae homozygous for esc ${ }^{21}$, class IV dendrites are indistinguishable from wild-type or heterozygous controls throughout embryogenesis and early larval stages (Fig. 2A,B). Notably, dendrites of class IV neurons in esc $^{21}$ mutants completely tile the body wall by $48 \mathrm{~h}$ AEL, demonstrating that dendritic territories are properly established in these mutants. Furthermore, as in wild-type embryos, ablation of class IV neurons in $e^{21} c^{21}$ mutant embryos leads to extensive invasion of the unoccupied territories by neighboring class IV neurons by 48 h AEL (data not shown), further demonstrating that dendritic territories are established similarly in $e s c^{21}$ mutants and wild-type controls.

Beginning at $48 \mathrm{~h}$ AEL, defects in class IV dendrites of esc $^{21}$ mutants become evident. By $96 \mathrm{~h} \mathrm{AEL}$, there are reproducible defects in the dendritic fields of $\operatorname{esc}^{21} \mathrm{mu}-$ tants, revealing that $\operatorname{esc}^{21}$ mutants are unable to maintain the complete coverage of the receptive field (Fig. 2C-E). Between 48 and $96 \mathrm{~h}$ AEL, there is significant larval growth and class IV dendrites normally grow concomitantly to maintain their complete coverage of the body wall. Dendrites in esc ${ }^{21}$ mutants continue to grow, but by 96 h AEL we observed a significant reduction in both the number of terminal dendritic branches and total dendritic length (Fig. 2F,G). In some severe cases $(\sim 10 \%$ of neurons sampled), there is a complete loss over major regions of the dendritic field (Fig. 2E), likely as a result of severing of major dendritic branches (see below). Therefore, although dendritic fields are established properly early in development, esc ${ }^{21}$ mutants appear to be defective in maintenance of dendritic fields.

Since ESC is a component of the PRC2 protein complex, we hypothesized that mutation of other components of PRC2 should similarly cause a gradual loss of dendritic coverage. Although null alleles of $\mathrm{Su}(z) 12$ or $E(z)$ rarely survive beyond early larval stages, hypomorphic alleles of $\operatorname{Su}(z) 12$ are viable through larval and pupal 
Parrish et al.

Figure 2. Reduction of PRC2 activity causes progressive defects in dendrite arborization. $(A-E)$ Live imaging of class IV ddaC neurons visualized with the pickpocket-EGFP reporter. Images show wild-type (wt) (A) or esc $^{21}$ homozygous mutant (B) larvae at $48 \mathrm{~h} \mathrm{AEL}$, and wild-type $(C)$ or $\operatorname{esc}^{21}$ homozygous mutant $(D-F)$ larvae at $96 \mathrm{~h}$ AEL. The arrow in $E$ points to a major dendritic trunk that has been severed close to the cell body. Dorsal is up, and anterior is left. Bar, $50 \mu \mathrm{m} .(F, G)$ Quantification of ddaC dendrite branch number $(F)$ and total dendrite length $(G)$ at 48 and $96 \mathrm{~h} \mathrm{AEL}$ in wild-type and esc $^{21}$ mutant larvae. Error bars represent one standard deviation, and asterisks $\left({ }^{\star}\right)$ denote $p<0.05$ relative to wild-type controls.
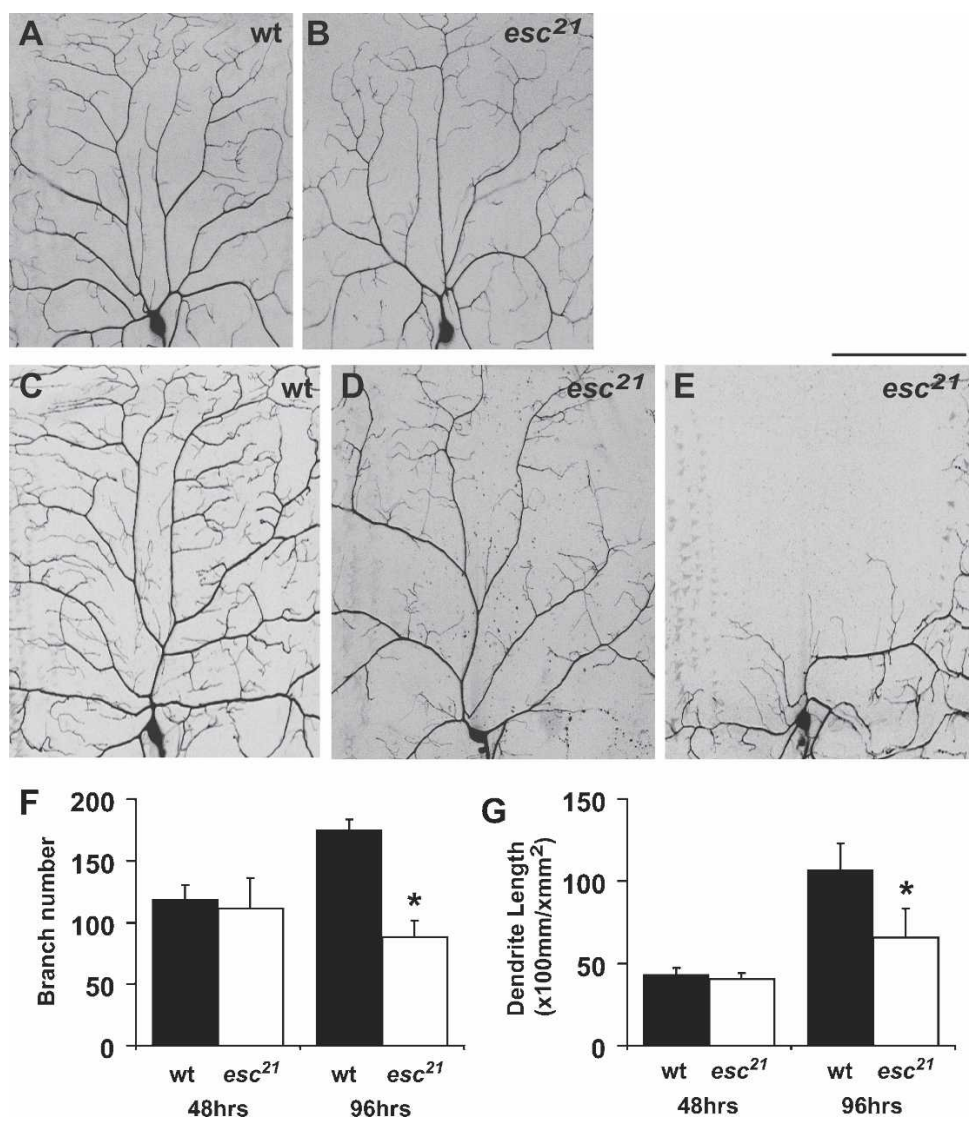

development. Mutants homozygous for the weak hypo-

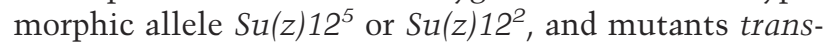
heterozygous for these alleles, showed dendrite defects that were qualitatively similar to those seen in $e \mathrm{sc}^{21}$ mutants (data not shown), further demonstrating that PRC2 is required for maintenance of class IV dendrites.

To more clearly establish that PcG genes are required for dendritic maintenance, we conducted time-lapse analysis of single neurons in heterozygous or homozygous esc ${ }^{21}$ mutant larvae. We focused our analysis on dendrite development at 72 and $96 \mathrm{~h} \mathrm{AEL} \mathrm{since} \mathrm{our} \mathrm{ear-}$ lier analysis revealed a requirement for $e s c^{21}$ in regulating dendrite development over this time frame. In $e s c^{21}$ heterozygotes, class IV dendrites grow extensively over this time period and show substantial rearrangement of terminal dendrites, including both growth and retraction (Fig. 3A,B). Likewise, class IV dendrites show extensive growth in $e s c^{21}$ mutants, demonstrating that $e s c^{21} \mathrm{mu}$ tant dendrites are not simply defective in growth (Fig. $3 \mathrm{C}, \mathrm{D})$. However, during this time interval, we observed several notable differences between class IV neurons in esc ${ }^{21}$ homozygous mutants and esc ${ }^{21}$ heterozygotes. First, some major dendritic trunks show signs of severing at $72 \mathrm{~h}$ AEL in $\operatorname{esc}^{21}$ mutants (arrow in Fig. $3 \mathrm{C}$ ), and this is never seen in controls. By $96 \mathrm{~h} \mathrm{AEL}$, the severed dendrite is almost completely eliminated in the esc mutant (Fig. 3D). Furthermore, between 72 and $96 \mathrm{~h} \mathrm{AEL,} \mathrm{there}$ is a significant decrease in the number of terminal den- drite branches in $e^{21} c^{21}$ mutants (Fig. 3D), whereas control class IV neurons show an increase in terminal dendrite branching over this same time period.

We next wanted to determine whether reducing the function of PRC1 components similarly caused defects in dendrite maintenance. Because Pc-null mutants die during embryonic stages, we used MARCM to generate homozygous control or $P c^{X T 109}$ mutant neuron clones and monitored development of single neurons using time-lapse microscopy. Maintenance defects are first apparent after $48 \mathrm{~h}$ AEL in mutants defective in PRC2 genes, and Gal 80 perdurance prevented us from imaging clones at earlier time points; therefore, we focused our analysis on larvae at 48-96 h AEL. Over this time period, dendrites in control clones grow and branch extensively and eliminate a small number of dendritic branches, as seen from the comparison of dendrites visualized at 72 and $96 \mathrm{~h} \mathrm{AEL} \mathrm{(Fig.} \mathrm{3E-G).} \mathrm{On} \mathrm{average,} \mathrm{the} \mathrm{terminal}$ branching in control class IV clones increased by $>30 \%$ $(33 \%, n=4)$. Over this same time period, $P c^{X T 109}$ mutant clones showed extensive growth of major dendritic branches and some terminal dendrites (Fig. 3H-J), further demonstrating that PcG mutants are not simply defective in dendritic growth. However, roughly a quarter of terminal dendrites were lost in $P c^{X T 109}$ mutants $(27 \%$, $n=4$ ), consistent with $P C$ playing an important role in dendrite maintenance. Furthermore, we observed fewer terminal branching/branch growth events (colored green in Fig. 3G,J) in $P c^{X T 109}$ mutant clones than in control 

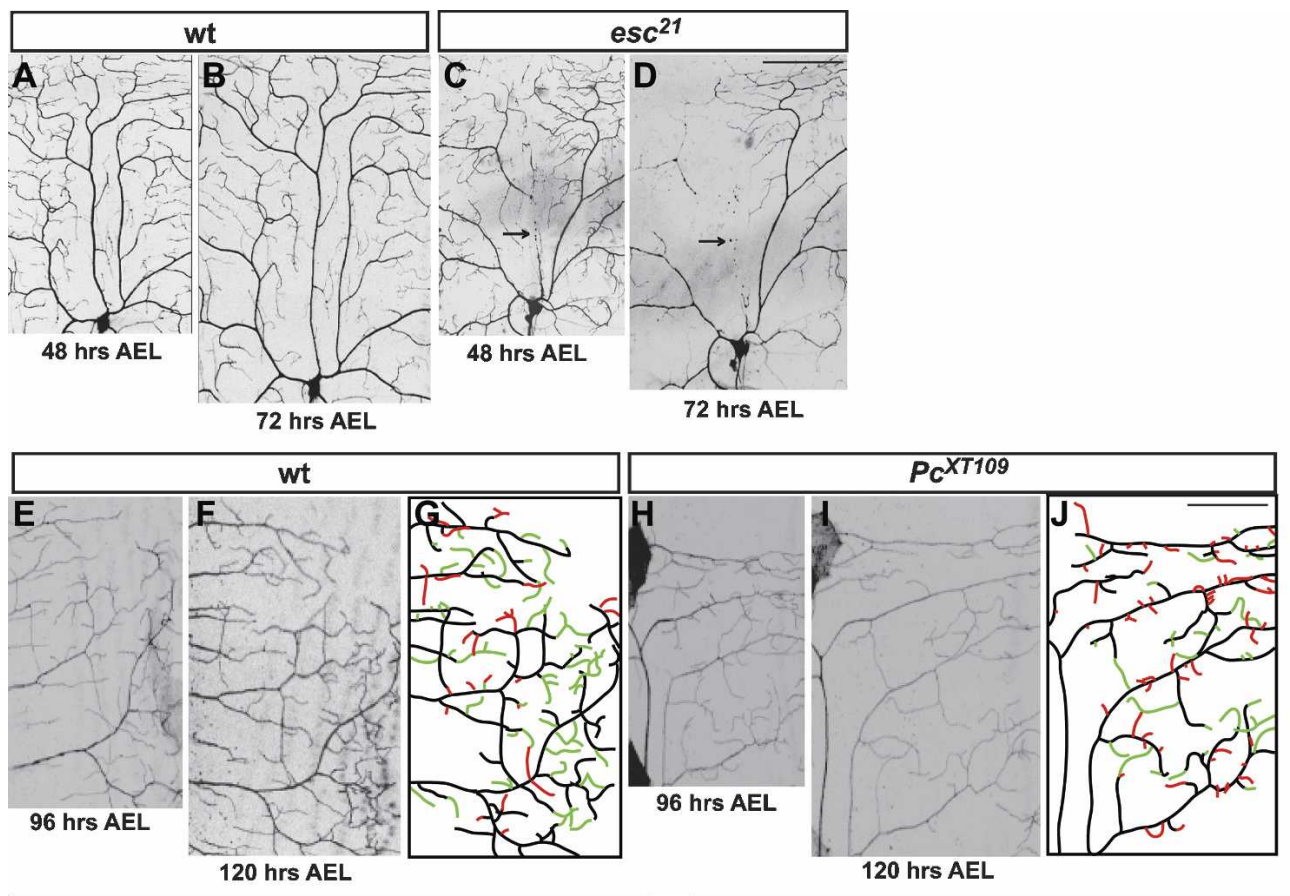

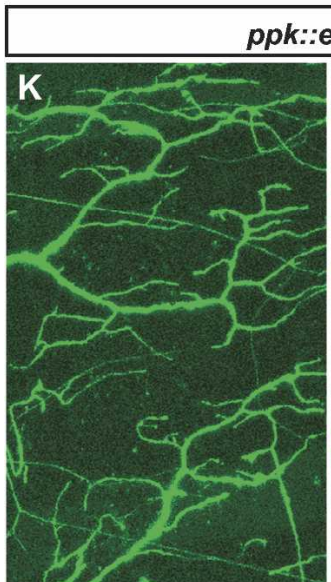

Time 0

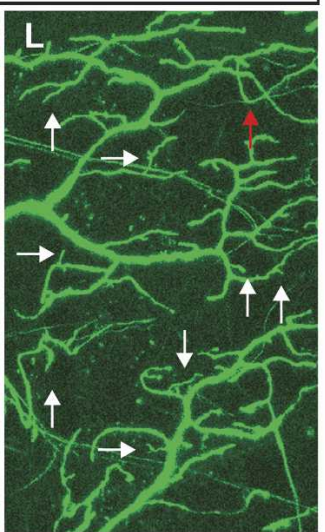

30 minutes

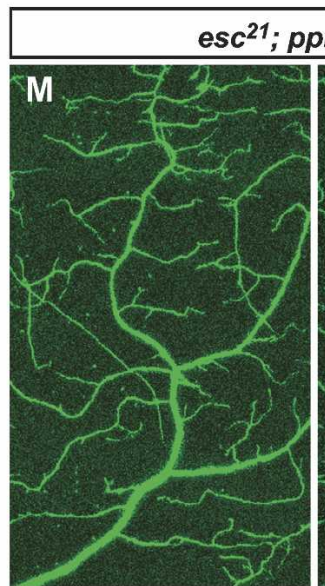

Time 0

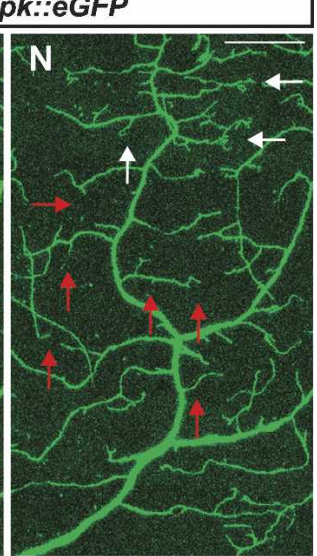

30 minutes

Figure 3. PRC1 and PRC2 are required for maintenance of dendritic arbors in class IV da neurons. $(A, B)$ Live imaging of an individual wild-type $(\mathrm{wt})$ ddaC neuron at $72 \mathrm{~h}(A)$ or $96 \mathrm{~h}(B)$ AEL. $(C, D)$ Live imaging of an individual esc ${ }^{21}$ mutant ddaC neuron at $72 \mathrm{~h}(C)$ or $96 \mathrm{~h}(D)$ AEL. Bar, $50 \mu \mathrm{m}$. (E-G) Live imaging of a wild-type MARCM clone at $72(E)$ or $96 \mathrm{~h}(F)$ AEL. $(G)$ The trace shows branches that have grown (green) or retracted (red) in the interval. Clone genotype: w, Gal4elav, UAS-mCD8::GFP/+; Frt2A/Frt2A. Bar, $50 \mu \mathrm{m}$. $(H-J)$ Live imaging of a Pc-MARCM clone at $72 \mathrm{~h}(H)$ or $96 \mathrm{~h}(I)$ AEL. (J) The trace shows branches that have grown (green) or retracted (red) in the interval. Clone genotype: w, Gal4 ${ }^{\text {elav }}$, UAS-mCD8::GFP/+; Pc ${ }^{X T 109}$ Frt2A/Pc ${ }^{X T 109}$ Frt2A. Bar, $50 \mu \mathrm{m}$. (K-N) Increased retraction and reduced growth of terminal dendrites in esc mutants. $(K, L)$ Time-lapse imaging of an individual wild-type ddaC neuron at $96 \mathrm{~h} \mathrm{AEL}(K)$ and following a 30-min time lapse $(L)$. White arrows denote instances of dendrite growth, and red arrows denote instances of dendrite retraction. $(M, N)$ Time-lapse imaging of an individual esc ${ }^{21}$ mutant ddaC neuron at $96 \mathrm{~h}$ AEL $(M)$ and following a 30-min time lapse $(N)$.

clones, suggesting that hampered growth of terminal branches may contribute to the dendrite maintenance defects. In general, the maintenance defects in $P c^{X T 109}$ mutant clones were less severe than those in $\operatorname{esc}^{21}$ homozygous mutant larvae. This could be an effect of protein perdurance in MARCM clones. Alternatively, there may be cell nonautonomous functions of PcG genes in dendrite development since PcG genes are widely expressed in both embryos and larvae.
Finally, to evaluate the basis of the dendrite maintenance defects with greater temporal resolution, we conducted time-lapse imaging of control and $e s c^{21}$ mutant third instar larvae over short time intervals beginning at $100 \mathrm{~h}$ AEL. Dendrite dynamics are readily apparent within 30-min intervals, with both growth (Fig. 3K,L, white arrows) and retraction (Fig. 3K,L, red arrows) occurring in control dendrites (Fig. 3K,L). In these experiments, we observed more growth events than retraction 
events in control dendrites. In $e s c^{21}$ mutants, we likewise observed both dendritic growth and retraction (Fig. $3 \mathrm{M}, \mathrm{N})$. However, the number and apparent rate of retraction events were greater than in control dendrites and greatly outnumbered the new branching/branch extension events in $\operatorname{esc}^{21}$ mutants. As a result, we observed an overall decrease in terminal dendritic length in $\operatorname{esc}^{21} \mathrm{mu}-$ tants. Therefore, it seems likely that increased retraction and reduced growth of terminal dendrites contribute to the maintenance defects we observed in PcG mutants. Taken together, our time-lapse analyses suggest that different mechanisms exist for the establishment and maintenance of dendritic fields, with the latter requiring PcG function.

We also investigated the possibility that the dendrite loss during larval development in esc ${ }^{21}$ mutants was due to dendrite degeneration resulting from neuronal death or defects in neighboring cells. In esc ${ }^{21}$ mutant third instar larvae, class IV neurons showed no sign of cell death as assessed by TUNEL or Annexin-V staining and excluded the vital dye propidum iodide, strongly suggesting that the neurons are not apoptotic or necrotic (data not shown). Furthermore, class IV neurons in esc ${ }^{21} \mathrm{mu}-$ tants persist through metamorphosis and into adulthood. Thus, the dendrite phenotypes are not due to cell death. Since dendrites of class IV neurons are sandwiched between larval muscle and the epidermis, we also tested whether the progressive dendrite defects could be a secondary consequence of defects in muscle or epidermis. We analyzed muscle morphology using a tropomyosin::GFP reporter and morphology of the epithelial cells of the epidermis by immunostaining larval fillets with an antibody against armadillo and found no differences between esc $^{21}$ mutants and control larvae using either of these markers (data not shown). Therefore, it seems likely that the dendrite defects reflect an autonomous requirement of PcG gene function in dendrite maintenance.

\section{PcG genes are not required for maintenance of axonal} arbors

Next we asked whether PcG genes are also required for maintenance of axon terminal projections. Although esc $^{21}$ mutants display defects in dendrite coverage by 96 $\mathrm{h}$ AEL, axons of class IV neurons in $\operatorname{esc}^{21}$ mutants enter the CNS at the appropriate position (Fig. 4A,B were obtained from the same larvae and at the same time as Fig. 2C,D, respectively). Furthermore, the overall morphology of class IV axons in the ventral nerve cord was indistinguishable from wild-type controls, demonstrating that class IV axons are not grossly affected in esc mutants.

Since potential defects in axon terminals would likely be difficult to resolve with the $p p k::$ EGFP marker that labeled all class IV axons, we used MARCM to label single neuron control or mutant clones. Each of the class IV neurons ( $\mathrm{ddaC}, \mathrm{v}^{\prime} \mathrm{ada}$, and $\mathrm{vdaB}$ ) projects its axons to the same medial position on the innermost FasII-positive fascicle in the CNS, and terminal arborization of each of
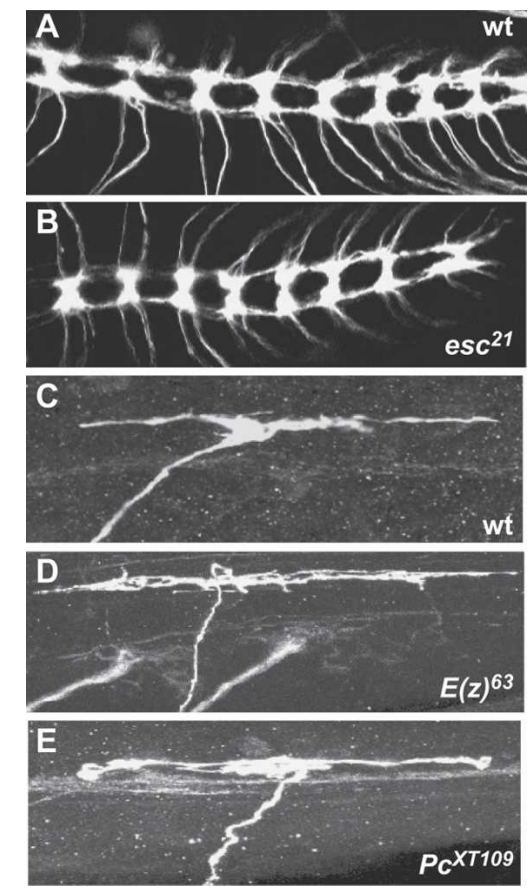

Figure 4. PcG mutants are not defective in maintenance of axon terminals. $(A, B)$ Axons of class IV neurons were visualized in the ventral nerve cord using $p p k::$ EGFP. Images of class IV axon projections from wild-type $(A)$ or $\operatorname{esc}^{21}$ mutants $(B)$ were taken from the same larvae and at the same time as images in Figure 3, B and D, respectively. (C-E) Axon terminals of control $(C), E(z)^{63}(D)$, and $P c^{X T 109}(E)$ MARCM clones. Clone genotypes were the same as in Figure 1. Representative clones without contralateral projections are shown, but we also observed contralateral projections in control, $E(z)^{63}$, and $P c^{X T 109}$ mutant clones with approximately the same frequency.

the class IV neurons is stereotyped (Merritt and Whitington 1995; Schrader and Merritt 2000; Grueber et al. 2007). For example, the axonal projection of ddaC terminates on the innermost fascicle and sends ipsilateral branches both anteriorly and posteriorly (Fig. 4C). In some cases, the axon also branches near its entry point into the VNC to send a collateral branch toward the midline. Axons of $E(z)^{63}$ or $P c^{X T 109}$ mutant ddaC clones occupy a similar fascicular position in the VNC and show very similar arborization patterns as wild-type controls (Fig. 4D,E). Furthermore, axon terminals of $E(z)^{63}$ or $P c^{X T 109}$ mutant $v^{\prime}$ ada or vdab clones are also indistinguishable from wild-type controls (data not shown). Therefore, PcG function appears to be specifically required for dendrite maintenance in class IV neurons.

\section{BX-C gene expression is down-regulated specifically in larval class IV neurons}

Several studies have established the important role of PcG genes in regulating Hox gene expression, and cisregulatory sequences termed PREs that are recognized by PcG proteins have been identified in the BX-C complex of Hox genes (Struhl 1983; Simon et al. 1992; Ringrose 
and Paro 2004). Therefore, we next characterized the pattern of $\mathrm{BX}-\mathrm{C}$ gene expression in da neurons. We found that the Bithorax complex (BX-C) proteins Ubx, AbdA, and $\mathrm{AbdB}$ are expressed in segmentally repeating stereotyped patterns in the Drosophila embryonic PNS (Fig. 5; Supplementary Fig. S2). Ubx is expressed in all embryonic da neurons, as shown by colocalization with the pan-da neuron enhancer trap line E7-2-36 (Fig. 5A-C); and is additionally expressed in es neurons, tracheal dendrite (td) neurons, and bd neurons of the PNS (data not shown). Furthermore, Ubx is expressed at roughly equivalent levels in class IV da neurons (indicated with white arrowhead) and other embryonic da neurons (Fig. 5G; data not shown). The BX-C proteins Abd-A and Abd-B showed similar patterns of expression in the PNS (Fig. 5H-J,N; Supplementary Fig. S2).

We next monitored Hox gene expression in late third instar larvae at $120 \mathrm{~h}$ AEL. As shown in Figure 5, D-F, Ubx is still highly expressed in most sensory neurons (visualized with anti-HRP antibodies in Fig. 5E) in third instar larvae. However, Ubx expression is almost undetectable in class IV neurons $(\mathrm{ddaC}$; indicated with arrow in Fig. 5E); the level of Ubx protein in class IV neurons relative to other da neurons (measured as relative pixel intensities from immunofluorescence) is reduced by more than fivefold as development progresses from embryonic to third instar larval stages (Fig. 5G). Similarly, the expression level of AbdA and AbdB in class IV neu- rons relative to other da neurons was reduced by nearly fivefold between embryonic and third instar larval stages (Fig. 5K-N; Supplementary Fig. S2). Our study thus revealed that the BX-C Hox genes are specifically downregulated in class IV neurons.

\section{$B X-C$ genes are inappropriately expressed in class $I V$ neurons of PcG mutants}

Since expression of BX-C genes is down-regulated in class IV neurons at approximately the time when PcG genes are required for dendritic maintenance, we wanted to determine whether BX-C expression was deregulated in class IV neurons defective in PcG function. To investigate this possibility, we again took advantage of the late lethal phase of $\operatorname{esc}^{21}$-null mutants and analyzed BX-C expression in $e s c^{21}$ homozygous mutant third instar larvae. As shown in Figure 6, A-C, the level of Ubx in class IV neurons (ddaC; marked by arrowhead) relative to other da neurons is significantly increased in esc ${ }^{21}$ mutant larvae compared with wild-type controls. Similarly, AbdA protein is inappropriately maintained at high levels in class IV neurons of $\operatorname{esc}^{21}$ mutant larvae /data not shown). Finally, we monitored expression of Ubx in $E(z)^{63}$ mutant clones and found that Ubx expression is increased nearly threefold in $E(z)^{63}$ class IV ddaC clones relative to the contralateral $E(z)^{63} /+$ heterozygous ddaC neurons (Fig. 6D-F), whereas Ubx expression is not sig-
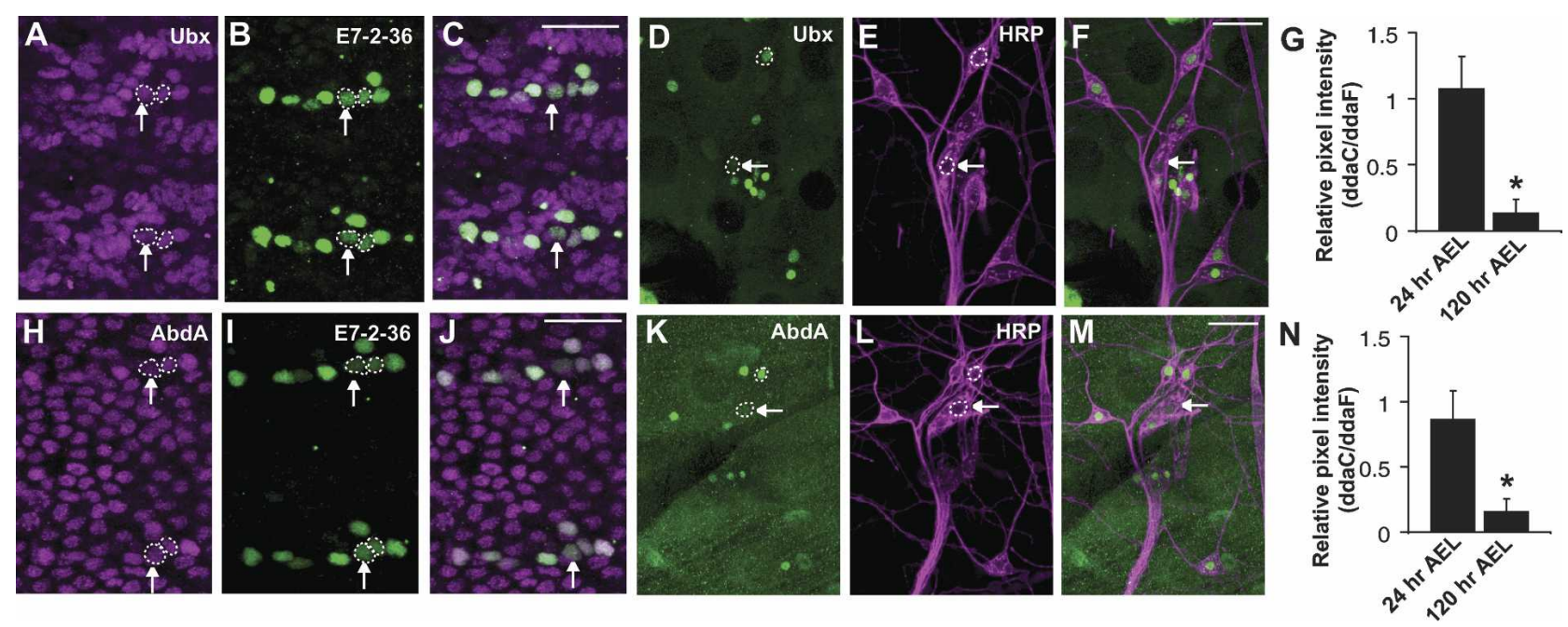

Figure 5. Bx-C Hox genes are expressed throughout the PNS and are down-regulated specifically in class IV da neurons. $(A-C)$ Anti-Ubx (FP3-38 antibody) staining $(A)$ in two neighboring segments (abdominal segments 3 and 4 ) of embryos carrying the md neuron enhancer trap E7-2-36 $(B)$. Here and in subsequent images the position of ddaC is marked with a white arrow, and both ddaC and ddaF are outlined in white. Anti-Ubx staining in class IV neurons was independently verified with the pickpocket-EGFP marker. A merge of the images is shown in $C$. In all images dorsal is up, and posterior is left. Bar, $50 \mu \mathrm{m}$. (D-F) Anti-Ubx staining in abdominal segment 3 of late third instar larvae $(D)$ costained with anti-HRP $(E)$ to label all sensory neurons. A merge of the images is shown in $F$. (G) Quantitation of Ubx expression levels at $24 \mathrm{~h}$ AEL and $120 \mathrm{~h} \mathrm{AEL} \mathrm{(third} \mathrm{instar).} \mathrm{To} \mathrm{facilitate} \mathrm{comparison} \mathrm{of} \mathrm{different} \mathrm{developmental}$ stages, the expression level is presented as a ratio of the mean pixel intensity of ddaC and another dorsal cluster da neuron, ddaF. Error bars represent one standard deviation, and asterisks $\left({ }^{\star}\right)$ denote $p<0.05$. (H- $\left.J\right)$ Anti-AbdA (6A8.12 antibody) staining $(H)$ in two neighboring segments (abdominal segments 3 and 4) of stage 16 embryos carrying the md neuron enhancer trap E7-2-36 (I). A merge of the images is shown in $J$. $(K-M)$ Anti-AbdA staining in abdominal segment 3 of late third instar larvae $(K)$ costained with anti-HRP $(L)$. A merge of the images is shown in $M$. $(N)$ Quantitation of AbdA expression levels at $24 \mathrm{~h} \mathrm{AEL}$ and $120 \mathrm{~h}$ AEL (third instar). As in $G$, the expression level is presented as a ratio of the mean pixel intensity of ddaC and ddaF. Error bars represent one standard deviation, and asterisks $\left({ }^{\star}\right)$ denote $p<0.05$. 

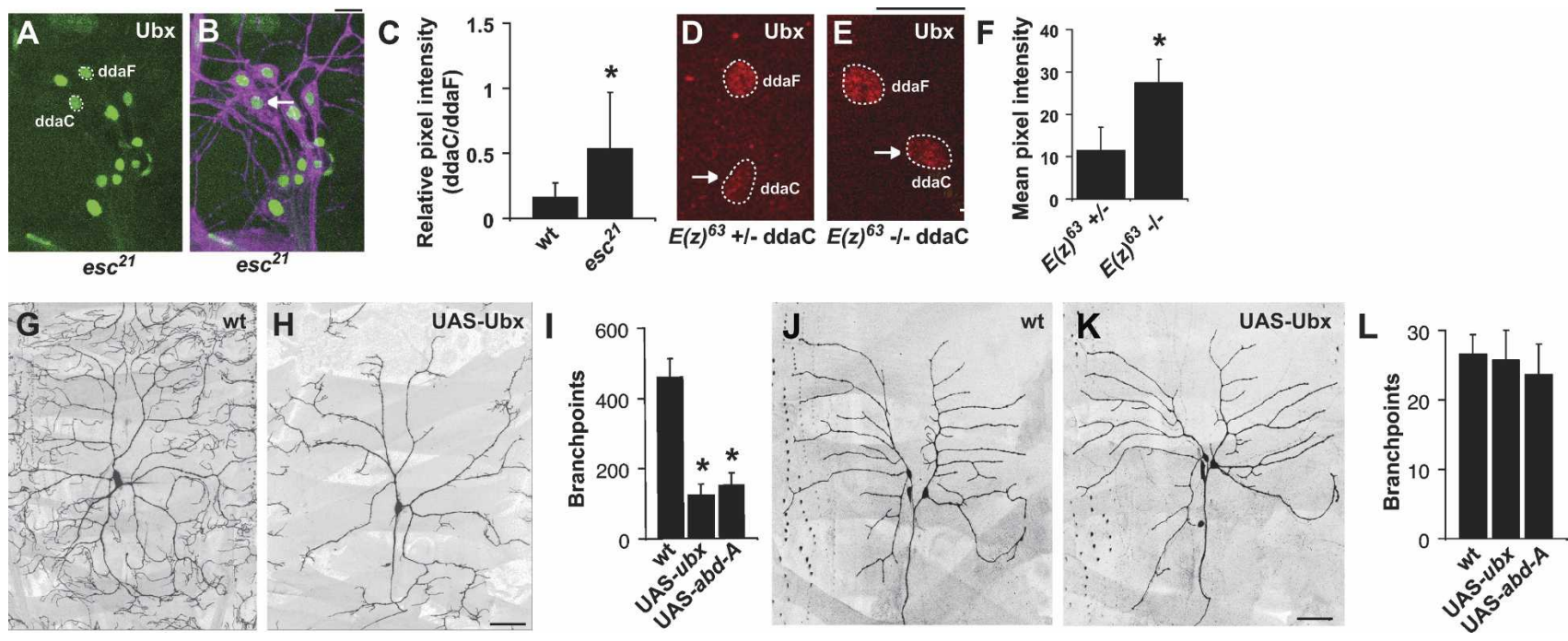

Figure 6. Esc is required for down-regulation of BX-C genes in class IV neurons. $(A, B)$ Anti-Ubx staining at $120 \mathrm{~h}$ AEL $(A)$ costained with anti-HRP $(B)$. Dorsal is up, posterior is left. Bar, $50 \mathrm{~mm} .(C)$ Quantitation of Ubx relative pixel intensity. The values presented are ratios of the mean pixel intensities of Ubx staining in wild-type (wt) or esc ${ }^{21}$ mutant ddaC (class IV) and ddaF (class III) neurons (both outlined with a white dashed line); $n=5$. $(D, E)$ Anti-Ubx staining in $E(z)^{63} /+(D)$ or $E(z)^{63} / E(z)^{63}(E)$ ddaC neurons. $E(z)^{63} /+$ ddaC neurons that were imaged were located contralateral to $E(z)^{63} / E(z)^{63}$ clones. $(F)$ Quantitation of the mean pixel intensity of anti-Ubx staining in ddaC neurons. Similar calculations were performed for the mean pixel intensities of other classes of da neurons in $E(z)^{63} /+$ heterozygotes or $E(z)^{63} / E(z)^{63}$ clones, and values were not significantly different; $n=6$. $(G-I)$ ppk-GAL4 driving expression of UASmCD8::GFP $(G)$ or UAS-mCD8::GFP and UAS-Ubx $(H)$ in class IV da neurons. Third instar larval fillets were stained with $\alpha$-CD8 antibody. The total number of dendrite branchpoints is quantified in $I$. Error bars represent one standard deviation, and asterisks $\left({ }^{\star}\right)$ denote $p<0.05$ relative to wild-type controls. $(J-L)$ GAL4 ${ }^{221}$ driving expression of UAS-mCD8::GFP $(J)$ or UAS-mCD8::GFP and UAS-Ubx $(K)$ in class I da neurons. Third instar larval fillets were stained with $\alpha$-CD8 antibody, and the number of dendrite branchpoints was quantified in $L$.

nificantly affected in other classes of $E(z)^{63}$ mutant da neurons (data not shown). Therefore, ESC and E(z) are required for proper down-regulation of BX-C expression in class IV neurons.

\section{Post-mitotic overexpression of $B \mathrm{X}$ - $C$ genes prevents proper dendrite arborization in class IV neurons}

Since BX-C genes are normally down-regulated in larval class IV neurons, we wanted to determine whether sustained post-mitotic expression of BX-C genes in otherwise wild-type class IV neurons was sufficient to affect dendrite arborization. We used ppk-Gal4, which is expressed almost exclusively in post-mitotic class IV da neurons, to drive expression of UAS-Ubx or UAS-abd-A and found that sustained expression of either $U b x$ or $a b d-A$ was sufficient to limit both dendritic branching and total dendritic length in class IV neurons (Fig. 6G-I). Since BX-C gene expression is maintained at high levels in other da neurons, we would expect that overexpression of BX-C genes should have little or no effect on dendrite development in other da neurons. Indeed, overexpression of $U b x$ or $a b d-A$ had no obvious effect on the dendrite arborization patterns of class I, II, or III da neurons (Fig. 6J-L; data not shown). On the other hand, overexpression of other transcription factors that are required for proper dendrite development in da neurons led to increased branching, reduced branching, altered branch- ing, and in many cases, no obvious defects (Parrish et al. 2006), indicating that the dendrite defects caused by overexpression of Hox genes are not generally caused by overexpression of transcription factors. Thus, downregulation of Hox genes in class IV neurons is likely one aspect of a transcriptional program regulating class IVspecific dendrite development.

In addition to Hox genes, we have analyzed alleles of $>20$ other putative PcG target genes for roles in establishment and/or maintenance of dendritic tiling. Although several of these putative PcG genes have been implicated in development of da neuron dendrites, including seq, lbe, and trh (Brenman et al. 2001; Parrish et al. 2006), none of the mutant alleles tested had any apparent defects in dendritic tiling or maintenance (Table 1). These findings, together with the observations that PcG genes regulate expression of Hox genes in class IV neurons and Hox gene function is required for proper establishment of dendritic tiling in class IV neurons, further suggest that Hox genes may be one of the important targets of PcG genes in regulation of dendrite maintenance.

\section{Hox genes modulate terminal dendrite dynamics in class IV neurons}

Since Hox genes are normally down-regulated at the time when PcG gene function is required for dendrite 
Table 1. Alleles of putative PcG-target genes that had no effect on establishment or maintenance of dendritic tiling in class IV neurons

\begin{tabular}{|c|c|c|}
\hline Gene & Allele & $\begin{array}{l}\text { Assay used to analyze } \\
\text { ddaC dendrites }\end{array}$ \\
\hline salm & $\operatorname{salm}^{1}$ & MARCM \\
\hline bar-h2 & UAS-barh2 & ppk-Gal4-driven overexpression \\
\hline $\operatorname{cg} 7417$ & $\operatorname{cg} 7417^{201 Y}$ & ppk-GFP in mutant larvae \\
\hline cad & $\mathrm{cad}^{2}$ & MARCM \\
\hline$C t B P$ & CtBP 03463 & MARCM \\
\hline Ten-m & Ten-m ${ }^{05309}$ & ppk-GFP in mutant larvae \\
\hline$c v-2$ & $c V-2^{1}$ & ppk-GFP in mutant larvae \\
\hline chic & chic $^{221}$ & MARCM \\
\hline tomosyn & tomosyn EP1359 & ppk-Gal4-driven overexpression \\
\hline hth & $h t h^{5 E 04}$ & MARCM \\
\hline map205 & $\operatorname{map} 205^{K G 05618}$ & $p p k$-GFP in mutant larvae \\
\hline$b-h 1$ & UAS-barh1 & ppk-Gal4-driven overexpression \\
\hline disco & $\operatorname{disco}^{1}$ & ppk-GFP in mutant larvae \\
\hline seq & $s e q^{22}$ & MARCM \\
\hline pnr & $p n r^{1}$ & MARCM \\
\hline lbe & $1 b e^{D f 311}$ & MARCM \\
\hline$v g$ & $U A S-V g$ & ppk-Gal4-driven overexpression \\
\hline trh & $t r h^{2}$ & MARCM \\
\hline t11 & $t 11^{L 49}$ & MARCM \\
\hline $\mathrm{klg}$ & $\mathrm{klg}^{r N 712}$ & ppk-GFP in mutant larvae \\
\hline fas & $\mathrm{fas}^{05488}$ & ppk-GFP in mutant larvae \\
\hline
\end{tabular}

maintenance and mutations in PcG genes caused sustained Hox gene expression in class IV neurons, we wanted to determine whether Hox genes contribute to establishment or maintenance of dendritic tiling in class IV neurons. To test this possibility, we examined the effects of Hox gene mutations on class IV dendrite development using MARCM. Class IV neurons homozygous for mutations in a single Hox gene such as $U b x^{1}$ or Ant $p^{25}$ showed no significant defects in dendrite development when compared with controls, possibly because of redundant functions of other Hox genes (data not shown). To circumvent the problem of redundancy, we analyzed $S c r^{C 1}, A n t p^{N s+R C 3}, U b x^{M X 12}$ mutant class IV neurons in larval segment T3, where other Hox genes are not detectibly expressed. Compared with wild-type control clones or $S c r^{C 1}, A n t p^{N s+R C 3}, U b x^{M X 12}$ heterozygous class IV neurons, homozygous $S c r^{C 1}, A n t p^{N s+R C 3}$, $U b x^{M X 12}$ clones showed severe defects in dendrite growth, branching, and coverage as well as axon fasciculation (Supplementary Fig. S3). Notably, the receptive field of homozygous $S c r^{C 1}, A n t p^{N s+R C 3}, U b x^{M X 12}$ clones is significantly reduced, demonstrating that establishment of tiling is impaired by mutation of Hox genes. These results indicate that Hox genes are required autonomously for axon and dendrite development of class IV neurons.

Regulation of dendrite maintenance by PcG genes involves modulation of terminal dendrite dynamics, with loss of PcG gene function causing an increase in terminal dendrite retraction and a decrease in terminal dendrite growth (Figs. 2, 3). If down-regulation of Hox genes is an important component of PcG-mediated regulation of dendrite maintenance, then loss of Hox gene function and loss of PcG gene function should have opposite effects on terminal dendrite dynamics. To examine this possibility, we conducted time-lapse analysis of ddaC wild-type control MARCM clones or $\mathrm{Scr}^{\mathrm{C} 1}$, $A n t p^{N s+R C 3}, U b x^{M X 12}$ homozygous mutant MARCM clones. We imaged ddaC neurons at $80 \mathrm{~h}$ AEL and again at $96 \mathrm{~h} \mathrm{AEL}$, a time at which hox genes are still present at high levels although down-regulation of hox gene expression is already apparent (Supplementary Fig. S4). Over this time interval, the dendritic field of both wildtype and mutant neurons expanded to a similar extent as a result of growth of major dendrites (data not shown). In wild-type control neurons, extensive growth and retraction of dendrite terminals was evident over the time lapse (Fig. 7A-C). Approximately $40 \%$ of the terminal dendrites (31 of 78 on average) in each wild-type neuron displayed dynamic behavior (Fig. 7I), and more than half of these dynamic terminals (19 of 31 ) were growing (Fig. 7J).

Although the major dendrites of wild-type and $S c r^{C 1}$, $A n t p^{N s+R C 3}, U b x^{M X 12}$ mutant neurons grew to a similar extent, Scr ${ }^{11}, A n t p^{N s+R C 3}, U b x^{M X 12}$ mutant neurons had an increased number of terminal dendrites when compared with wild-type controls (Fig. 7G). Terminal dendrites in $\mathrm{Scr}^{C 1}, A n t p^{N s+R C 3}, \mathrm{Ubx}^{M X 12}$ mutant clones were more likely to display dynamic behavior over the time interval than wild-type controls (Fig. 7H,I), and the increase in dynamic behavior was the result of increased dendrite branch initiation/growth (Fig. 7J). Whereas terminal dendrite growth was increased, the number of dendrite retractions was not significantly changed in $\mathrm{Scr}^{C 1}$, Ant $p^{N s+R C 3}, U b x^{M X 12}$ mutant neurons (Fig. 7K). Therefore, loss of Hox gene function affects the dynamics of terminal dendrites in class IV neurons, leading to an increase in the number of dendrite growth events. Notably, this is the opposite of what we observed in PcG mutant class IV neurons.

Analysis of genetic interactions between PcG genes and genes that regulate dendritic branching in class IV da neurons

Several genes including nanos, pumilio, rac, and cut have been shown to regulate dendrite branching and arborization in class IV neurons (Grueber et al. 2003a; Lee et al. 2003; Ye et al. 2004). It is possible that deregulation of the activities of these genes could contribute to the phenotypes we observed in PcG mutant neurons. However, we did not observe any abnormalities in dendrite development in larvae trans-heterozygous for PcG mutants and mutant alleles of nanos, pumilio, rac, or cut (data not shown). In mouse embryonic fibroblasts, PRC2 has been shown to function in the cytoplasm to regulate actin polymerization, and loss of PRC2 activity can be rescued by expression of activated Cdc42 or Rac (Su et al. 2005). Although overexpression of activated Rac or Cdc42 induced robust overbranching in class IV dendrites, overexpression of neither was sufficient to rescue the dendrite defects of $e s c^{21}$ mutants (data not shown). In $\mathrm{da}$ neurons, the expression level of the homeodomain 
Parrish et al.
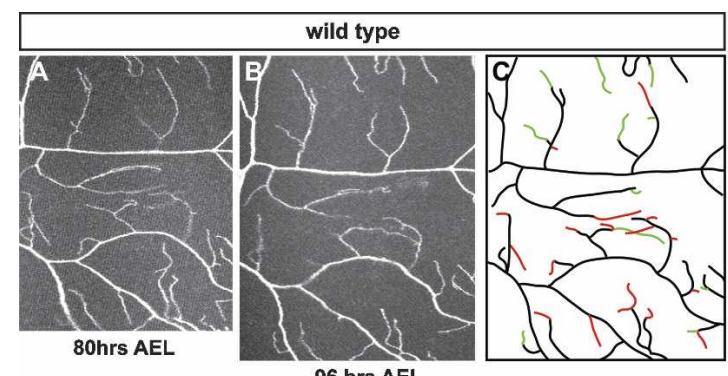

96 hrs AEL

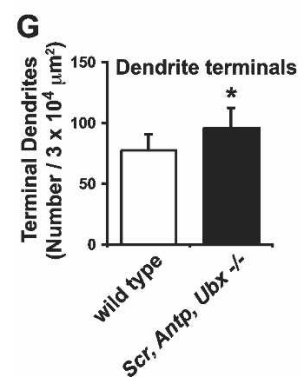

H $\frac{\infty}{\pi}$

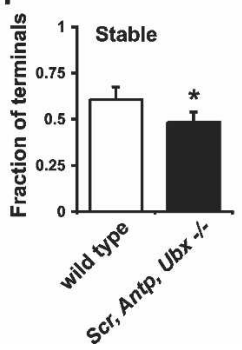

I

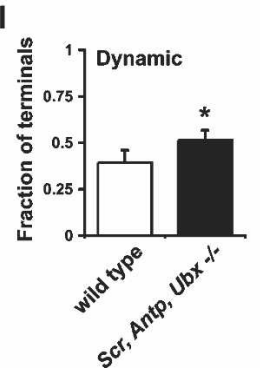

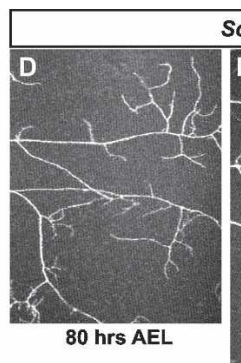

$S c r^{C 1}, A n t p^{N S+R C 3}, U b x^{M \times 12}$

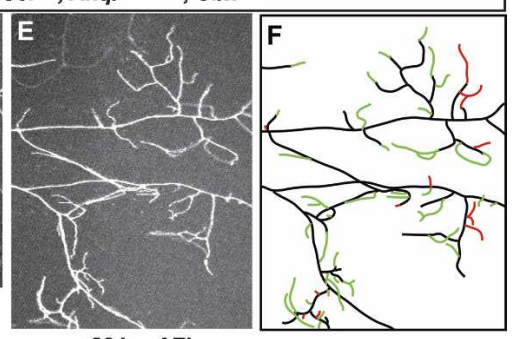

$96 \mathrm{hrs}$ AEL
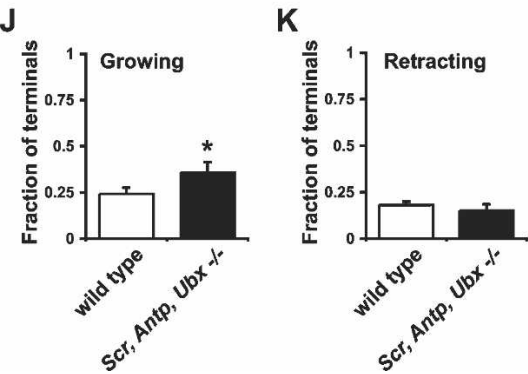

Figure 7. Hox genes regulate terminal dendrite dynamics. Time-lapse imaging of representative control $(A-C)$ or $S c r^{C 1}, A n t p^{N s+R C 3}$, $U b x^{M X 12-1-}(D-F)$ class IV ddaC MARCM clones. Clones were imaged at $80 \mathrm{~h}$ AEL $(A, D)$ and again at $100 \mathrm{~h} \mathrm{AEL}(B, E)$, and branch dynamics are depicted in traces $(C, F)$. The dynamic behavior of terminal dendrites was assessed for a $150 \times 200$ - $\mu \mathrm{m}$ region in the 100 - $\mathrm{h}$ time point with the soma centered on the AP axis and the region of interest extending $200 \mathrm{~mm}$ dorsally. Comparable portions of this region are shown for representative clones in $A-F .(C, F)$ Dynamics are represented in traces of 100-h dendrites. Terminal dendrites were scored as stable (colored black) if they were the same length in both images and were scored as dynamic if the terminal branch length increased via growth/branch initiation (green) or decreased via branch retraction/elimination (red). Terminal dendrite dynamics were measured from time-lapse images of nine control or mutant MARCM clones, and the mean total number of dendrite terminals $(G)$, ratio of stable dendrite terminals $(H)$, dynamic dendrite terminals $(I)$, growing dendrite terminals $(J)$, and retracting dendrite terminals $(K)$ for MARCM clones of each genotype are shown. Error bars represent one standard deviation, and asterisks $\left({ }^{\star}\right)$ denote $p<0.05$ relative to wild-type controls.

transcription factor Cut correlates with dendritic complexity (Grueber et al. 2003a), but Cut expression was not detectably altered in the PNS of PcG mutants /data not shown). Finally, misexpression of the transcription factor Abrupt in class IV neurons causes a significant reduction in dendritic complexity (Li et al. 2004; Sugimura et al. 2004), but Abrupt expression is not affected in the PNS of PcG mutants (data not shown). Therefore, PcG genes appear to specifically regulate the BX-C Hox genes in class IV neurons but have no detectable effects or interactions with nanos, pumilio, rac, cdc42, abrupt, or cut to regulate dendrite development in class IV neurons.

\section{PcG genes interact with wts to regulate dendrite development and Hox gene expression}

During the course of our studies, we noted that mutations in PcG genes phenocopied mutations in the tumor suppressor gene warts/lats (wts), which encodes an NDR-family kinase. Similar to PcG mutants, mutations in wts or salvador (sav), which encodes an adaptor protein required for Wts activity, cause defects in maintenance of dendritic tiling in class IV neurons (Emoto et al. 2006). To test whether PcG genes and wts might function in the same genetic pathway to regulate dendrite maintenance, we tested for genetic interactions between components of the wts signaling pathway and PcG genes. As mentioned above, heterozygosity for null mutations in the PcG genes Pc, esc, E(z), or Su(z)12 caused no significant defects in dendrite morphogenesis (Fig. $1 \mathrm{H}, \mathrm{J})$. Likewise, heterozygosity for null alleles of wts, sav, or hippo (hpo), a tumor suppressor kinase that functions as an upstream regulator of wts, caused no discernable defects in dendrite development (Fig. 8A,B,D). However, trans-heterozygous combination of wts latsX1, $s a v^{3}$, or $h p o^{m g h 4}$ together with $P c^{3}$ caused a signification simplification of dendrites that was comparable to transheterozygous combinations of PcG mutants (Fig. 8C,D). Likewise, trans-heterozygous combination of wts ${ }^{\text {latsX1, }}$ $s a v^{3}$, or $h p o^{m g h 4}$ together with $E(z)^{63}$ or Sulz $\left(12^{4}\right.$ caused similar dendrite defects (data not shown). Thus, PcG genes and genes in the Wts signaling pathway genetically interact to regulate dendrite development.

In addition to Wts, Drosophila has one other NDRfamily kinase, Tricornered (Trc), that is required for establishment of dendritic tiling in class IV neurons (Emoto et al. 2004). Mutations in hpo cause defects in both the establishment and maintenance of dendritic tiling, and hpo genetically and physically interacts with trc, demonstrating that maintenance is linked to establishment of dendritic fields in class IV neurons (Emoto et al. 2006). Therefore, we wanted to determine whether PcG genes also interacted with trc to regulate establish- 


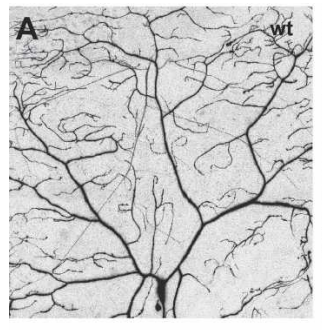

D

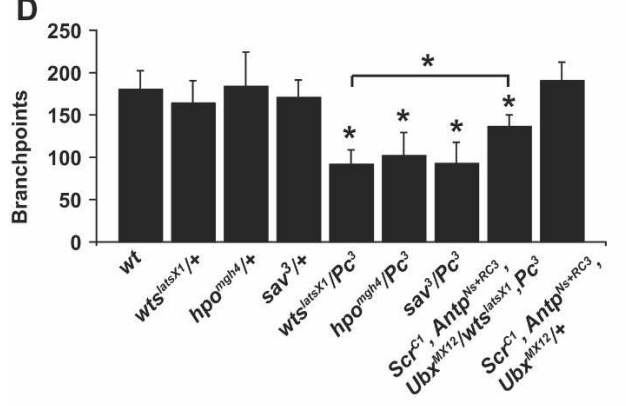

$\mathbf{F}$

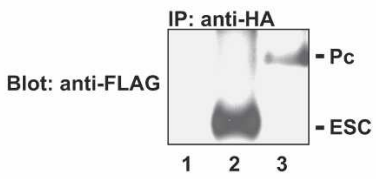

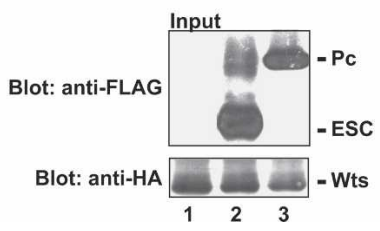
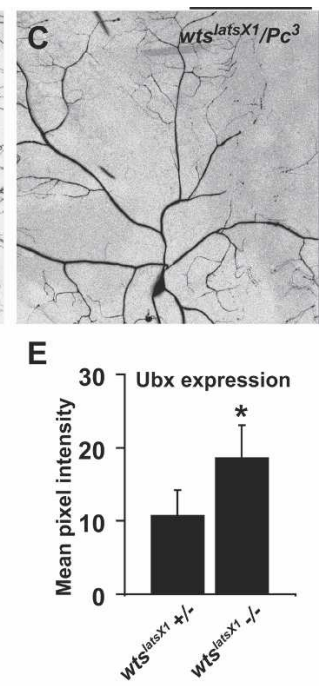

Figure 8. PcG genes interact with wts to regulate dendrite development. $(A-C)$ Live image of third instar class IV ddaC neuron visualized using pickpocket-Gal4, UAS$m C D 8:: G F P$ in wild-type $(A)$, wts ${ }^{l a t s X 1} /+$ heterozygous, $(B)$ or $w$ ts $^{\text {lats } X 1} / P C^{3}$ trans-heterozygous $(C)$ larva. Anterior is left, and dorsal is up. Bar, $50 \mu \mathrm{m}$. (D) Quantitation of dendrite branchpoints normalized to total dendritic length in ddaC of wild-type, wts $s^{1 a t s X 1} /+, s a v^{3} /+, h p o^{m g h} /$ + , wts ${ }^{1 a t s X 1} / P c^{3}, s a v^{3} / P c^{3}$, or $h p o^{m g h 4} / P c^{3}, w t s^{1 a t s X 1}, P c^{3} /$ $S c r^{C 1}, A n t p^{N s+R C 3}$, or $U b x^{M X 12}$ or $S c r^{C 1}, A n t p^{N s+R C 3}$, $U b x^{M X 12} /+$ larvae. Error bars represent one standard deviation, and asterisks $\left({ }^{\star}\right)$ denote $p<0.05$ relative to wildtype controls. $(E)$ Quantitation of the mean pixel intensity of anti-Ubx staining in ddaC neurons. wts $s^{1 a t s X 1} /+$ heterozygous ddaC neurons that were located contralateral to $w s^{1 a t s X 1} / w s^{1 a t s X 1}$ homozygous ddaC clones were used for controls; $n=5$. $(F)$ Complex formation by PcG proteins and Wts. Drosophila S2 cells were transfected with Wts-HA alone (lane 1), Wts-HA and ESC-Flag (lane 2), or Wts-HA and Pc-Flag (lane 3), and the lysates were immunoprecipitated with anti-HA antibody. Representative Western blots of the immunoprecipitates (left panel; probed with anti-Flag antibody) and lysates used as input for the immunoprecipitates (right panel; probed with anti-Flag or anti-HA antibody) are shown. ment of dendritic fields in class IV neurons. Heterozygosity of $P c^{3}, t r c^{1}$, or trans-heterozygosity of $P c^{3}$ lor any other PcG mutations) and $t r c^{1}$ had no effect on dendritic tiling when compared with wild-type controls, whereas trans-heterozygosity of mutants in trc and fry, which encodes a putative adaptor protein required for Trc function in dendritic tiling, caused a significant increase in dendrite crossing points (Supplementary Fig. S5). Furthermore, we saw no significant increase in the number of dendritic crossing points at any stage in PcG mutant MARCM clones when compared with wild-type controls. Thus, PcG genes appear to function together with the Wts pathway in regulation of dendritic maintenance but not the Trc pathway in establishment of dendritic tiling.

Mutations in PcG genes or Wts pathway genes cause defects in dendrite maintenance that are likely the result of increased terminal dendrite retraction and reduced terminal branch growth (Figs. 2, 3; Emoto et al. 2004), whereas mutations in Hox genes lead to increased terminal dendrite growth. If regulation of Hox gene expression is an important component of PcG/Wts-mediated regulation of dendritic maintenance, then reducing the Hox gene copy number might be sufficient to rescue the dendrite defects we observed in PcG/wts trans-heterozygous mutants. As shown in Figure 8D, reducing the Hox gene dosage significantly ameliorates the dendrite defects of $\mathrm{Pc}^{3} / \mathrm{wts}^{\text {lats } X 1}$ trans-heterozygous mutants, whereas trans-heterozygosity of $\mathrm{Scr}^{\mathrm{C1}}, \mathrm{Antp}^{\mathrm{Ns}+\mathrm{RC}}$, $U b x^{M X 12}$ by itself had no effects on dendrite branching, suggesting that PcG genes and Wts pathway genes function in a genetic pathway for dendritic maintenance that involves regulation of Hox gene expression.
Loss-of-function mutations in PcG genes cause misexpression of Hox genes in class IV da neurons, and in an attempt to establish an epistatic relationship between Hox genes and wts, we tested whether loss of wts could similarly cause misexpression of Hox genes. Ubx was expressed at significantly higher levels

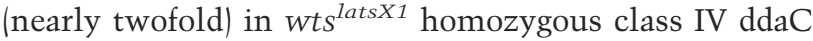
clones compared with contralateral wts ${ }^{\text {latsX1}} /+$ heterozygous class IV ddaC neurons (Fig. 8E). Similar to PcG mutants, wts ${ }^{\text {lats } X 1}$ had no obvious effect on Hox expression in other classes of da neurons (data not shown). Since PcG proteins directly bind PREs to regulate Hox gene expression, these findings suggest that wts likely functions at the same step or upstream of PcG genes to regulate Hox gene expression and dendrite development.

Since Wts genetically interacts with PcG genes to regulate dendrite development, we tested whether Wts could physically associate with PcG proteins. We cotransfected Drosophila S2 cells with a Flag-tagged Pc or ESC construct and a hemagglutanin (HA)-tagged Wts construct and immunoprecipitated Wts with anti-Flag antibodies. As shown in Figure 8F, ESC, and to a lesser degree Pc, coimmunoprecipitated with Wts, demonstrating that Wts can physically associate with PcG proteins. These findings suggest that Wts preferentially associates with PRC2, and we have found that Wts and another PRC2 component, Su(z)12, can coimmunoprecipitate as well (data not shown). Therefore, it seems likely that Wts and PcG proteins function together at the same step in a pathway to regulate Hox gene expression and dendrite development. 
PcG genes regulate Hox gene expression in a variety of contexts, and to determine whether the interaction between PcG genes and Wts signaling was confined to da neurons or functional in other contexts as well, we tested for trans-heterozygous interactions between PcG mutants and Wts signaling pathway mutants in regulating expression of the Hox gene Sex combs reduced (Scr). Derepression of Scr in the second and third leg discs causes a homeotic transformation, leading to formation of a first leg structure, the sex comb. On its own, heterozygosity for wts ${ }^{\text {latsX1 }}, h p o^{m g h 4}$, or $e s c^{21}$ was not sufficient for formation of ectopic sex combs on the second and third legs (Fig. 9A,B). Heterozygosity for $P c^{3}$, on the other hand, led to an average of 1.2 legs with ectopic sex combs, and this was significantly increased when $P c^{3}$ was trans-heterozygous with wts ${ }^{\text {latsX1 }}, h_{p o} o^{\text {mgh4 }}$, or esc ${ }^{21}$ (Fig. 9A,B). Notably, wts ${ }^{\text {latsX1 }}$ or hpo ${ }^{\text {mgh4 }}$ interacted with $P c^{3}$ to produce nearly as many ectopic sex combs as $e s c^{21}$. Furthermore, we observed similar interactions
A

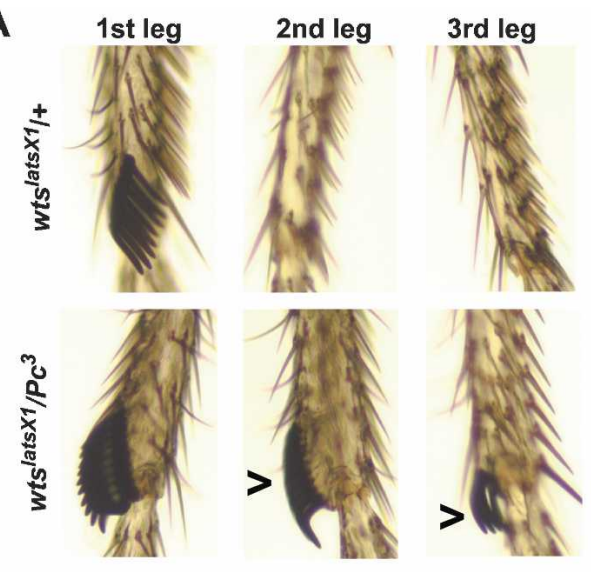

B

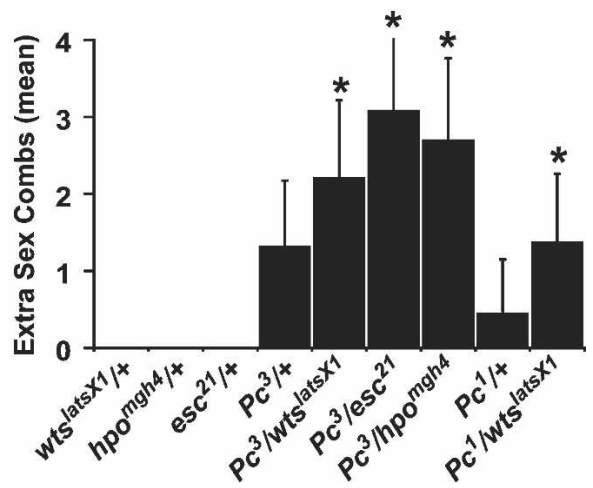

Figure 9. wts interacts with PcG genes to regulate ScR expression. (A) Representative bright-field images of male legs in $w_{t s}{ }^{\text {lats } X 1} /+$ heterozygotes (top panels) or wts ${ }^{\text {lats } X 1} / P c^{3}$ heterozygotes (bottom panels). Ectopic sex combs, which are normally first leg structures, are indicated with an arrowhead. Additional teeth are present in sex combs of the first leg, and ectopic sex combs are present on the second and third legs of wts ${ }^{\text {lats } X 1} / P C^{3}$ heterozygotes. $(B)$ Quantitation of the mean number of ectopic sex combs on the second and third legs (maximum $=4$ ) of males of the indicated genotypes. Error bars represent one standard deviation, and asterisks $\left({ }^{\star}\right)$ denote $p<0.05$ relative to wild-type controls. For each genotype, $n \geq 40$. with another allele of $P c\left(P c^{1}\right)$ and $w t s^{\text {lats } X 1}$. Therefore, the Wts signaling pathway likely interacts with PcG genes in a variety of cellular contexts.

\section{Discussion}

Dendrite arborization patterns are a hallmark of neuronal type; yet how dendritic arbors are maintained after they initially cover their receptive field is an important question that has received relatively little attention. The Drosophila PNS contains different classes of sensory neurons, each of which has a characteristic dendrite arborization pattern, providing a system for analysis of signals required to achieve specific dendrite arborization patterns. Class IV neurons are notable among sensory neurons because they are the only neurons whose dendrites provide a complete, nonredundant coverage of the body wall. We have found that the function of Polycomb group genes is required specifically in class IV da neurons to regulate dendrite development. In the absence of PcG gene function, class IV dendrites initially cover the proper receptive field but subsequently fail to maintain their coverage of the field. Time-lapse analysis of dendrite development in esc or Pc mutants suggests that a combination of reduced terminal dendrite growth and increased dendrite retraction likely accounts for the gradual loss of dendritic coverage in these mutants. Maintenance of axonal terminals in class IV da neurons is apparently unaffected by loss of PcG gene function, suggesting that PcG genes function as part of a program that specifically regulates dendrite stability.

\section{Different mechanisms for establishing and maintaining dendritic fields}

Establishment of dendritic territories in class IV neurons is regulated by homotypic repulsion /Grueber et al. 2003b; Sugimura et al. 2003), and this process proceeds normally in the absence of PcG function. In PcG mutants, class IV neurons tile the body wall by $48 \mathrm{~h}$ AEL, similar to wild-type controls. However, beginning at 48 $\mathrm{h}$ AEL, likely as a result of reduced dendritic growth and increased terminal dendrite retraction, class IV neurons of PcG mutants gradually lose their dendritic coverage. In contrast, the axon projections and terminal axonal arbors of PcG mutants show no obvious defects. Although we cannot rule out an early role for PcG genes in regulating axon development, our MARCM studies showed that PcG genes are required for the maintenance of dendrites but not axons in late larval development. Thus, different genetic programs appear to be responsible for the establishment and maintenance of dendritic fields, and for the maintenance of axons and dendrites.

\section{A role for Polycomb group genes in neuronal development}

It is well established that PcG genes participate in regulating several important developmental processes in- 
cluding expression of Hox genes for the specification of segmental identity. In comparison, much less is known about the function of PcG genes in neuronal development. Studies of the expression patterns of PcG genes and the consequences of overexpression of PcG genes suggest that PcG genes may affect the patterning of the vertebrate CNS along the anterior-posterior (AP) axis, analogous to their functions in specifying the body plan (Barnett et al. 2001; Kitaguchi et al. 2001; Kwon and Chung 2003). A recent study demonstrates that the PcG gene Polyhomeotic regulates aspects of neuronal diversity in the Drosophila CNS (Wang et al. 2006). Our study now links the function of PcG genes to maintenance of dendritic coverage of class IV sensory neurons. Thus it will be interesting to determine whether PcG genes play a conserved role in the regulation of dendrite maintenance.

Since Hox genes function in late aspects of neuronal specification and axon morphogenesis (Jungbluth et al. 1999; Liu et al. 2001; Merritt and Whitington 2002; Miguel-Aliaga and Thor 2004; Dasen et al. 2005), it seems possible that regulation of Hox genes by PcG genes may be important for aspects of post-mitotic neuronal morphogenesis, including dendrite development. We have found that the PcG genes esc and $E(z)$ are required for proper down-regulation of BX-C Hox gene expression in class IV neurons. The timing of this change in BX-C expression corresponds to the time frame during which PcG genes are required for dendritic maintenance. Furthermore, post-mitotic overexpression of BX-C genes in class IV da neurons, but not other classes of da neurons, is sufficient to cause defects in dendrite arborization, thus phenocopying the mutant effects of PcG genes. Finally, we have found that Hox genes are required cell-autonomously for dendrite development in class IV neurons, and loss of Hox gene function causes defects in terminal dendrite dynamics that are opposite to the defects caused by loss of PcG genes. Therefore, it seems likely that PcG genes regulate dendrite maintenance in part by temporally regulating BX-C Hox gene expression.

Several recent studies have focused on the identification of direct targets of PcG-mediated silencing, demonstrating that PcG genes regulate expression of distinct classes of genes in different cellular contexts (Boyer et al. 2006; Lee et al. 2006; Schwartz et al. 2006; Tolhuis et al. 2006). During Drosophila development, PRC proteins likely associate with $>100$ distinct loci, and the chromosome-associate profile of PRC proteins appears dynamic (Bracken et al. 2006; Klymenko et al. 2006). Therefore, identifying the targets of PcG-mediated silencing in a given developmental process has proven difficult. Thus far, we have analyzed alleles of $>20$ predicted targets of PcG-mediated silencing for roles in establishment or maintenance of dendritic tiling and have found a potential role only for Hox genes. Future studies will be required to identify additional targets of PcG-mediated silencing in regulation of dendrite maintenance.

Regulation of PcG function in class IV neurons

PcG genes are broadly expressed, so it seems likely that interactions with other factors or post-translational mechanisms may be responsible for the cell type-specific activity of PcG genes. Indeed, we have found that PcG genes genetically interact with components of the Wts signaling pathway to regulate dendrite development specifically in class IV neurons. Based on the observations that wts mutants also show derepression of Ubx in class IV neurons and that Wts can physically associate with PcG components, it seems likely that Wts may directly or indirectly influence the activity of PcG components. In proliferating cells, Wts phosphorylates the transcriptional coactivator Yorkie to regulate cell cycle progression and apoptosis, demonstrating that Wts can directly influence the activity of transcription factors (Huang et al. 2005). In support of a possible role for Wts directly modulating PcG function, several recent reports have documented roles for phosphorylation in regulating PcG function both in Drosophila and in vertebrates (Shindo et al. 2005; Su et al. 2005). Thus, it is possible that some of the components involved in PcG-mediated silencing are regulated by Wts phosphorylation. Alternatively, association of Wts with PcG proteins may facilitate Wtsmediated phosphorylation of chromatin substrates.

The tumor suppressor kinase Hpo regulates both establishment and maintenance of dendritic tiling in class IV neurons through its interactions with Trc and Wts, respectively (Emoto et al. 2006), but how Hpo coordinately regulates these downstream signaling pathways is currently unknown. Similar to mutations in wts, mutations in PcG genes interact with mutations in hpo to regulate dendrite maintenance but show no obvious interaction with trc, consistent with the observation that PcG gene function is dispensable for establishment of dendritic tiling. Although it is possible that different upstream signals control Hpo-mediated regulation of establishment and maintenance of dendritic tiling, the nature of such signals remain to be determined. Another possibility is that the activity of the Wts/PcG pathway could be antagonized by additional unknown factors that promote establishment of dendritic tiling.

In addition to their interaction in regulating dendrite maintenance, we have found that PcG genes and wts interact to regulate expression of the Hox gene Scr during leg development. This finding suggests that the Hpo/ Wts pathway may play a general role in contributing to PcG-mediated regulation of Hox gene expression. The presence of ectopic sex combs provides a very simple and sensitive readout of $w t s / \mathrm{PcG}$ gene interactions and should form the basis for conducting large-scale genetic screens to identify other genes that interact with wts or PcG genes and participate in this genetic pathway.

\section{Materials and methods}

Fly stocks

For visualizing class IV dendrites, we used pickpocket (ppk)GFP on the third chromosome in combination with the following mutant alleles: $\operatorname{esc}^{21}$ (null), Su(z) $12^{1}$ (antimorph), Su(z)12 ${ }^{2}$ (hypomorph), Su(z)124 (null), Su(z)12 $2^{5}$ (hypomorph), $P c^{1}$ (null), $P C^{3}$ (amorph/antimorph), wts ${ }^{\text {latsX1 }}$ (null), sav ${ }^{3}$ (null); hpo ${ }^{m g h 4}$ 
(null). For visualizing class I dendrites, we used Gal-4221, UASmCD8-GFP. Homozygous mutant chromosomes were identified by selecting against either Kruppel Gal-4, UAS-GFP (KrGFP) balancer chromosomes or balancer chromosomes marked with the dominant Tubby $(\mathrm{Tb})$ mutation.

\section{MARCM analysis}

MARCM studies were conducted essentially as described (Grueber et al. 2002). Briefly, esc ${ }^{21}$, Frt40A/Cyo, w; E(z) ${ }^{63}$, Frt 2A/TM6c, Su(z)124, Frt2A/TM6C, Su(z)12 ${ }^{1}$, Frt2A/TM6C, Pc XT109, Frt2a/TM6 Hu, esc ${ }^{21} /$ Cyo-GFP; Pc XT109, Frt2a/TM6B, esc $^{21} /$ Cyo-GFP; E(Z) $)^{63}$, Frt2a/TM6B, Frt82B, wts ${ }^{\text {latsX1 }} / T M 6 B$, Frt82B, Ubx ${ }^{1} / \mathrm{TM} 6 B$, Frt82B, Antp ${ }^{25}$, red, e/TM6B, Frt82B $\mathrm{Scr}^{C 1}, \mathrm{Antp}^{\mathrm{Ns}+\mathrm{RC}}, \mathrm{Ubx}^{\mathrm{MX12}} / \mathrm{TM} 6 \mathrm{~B}$, or w; Frt40a, w; Frt2a, or W; Frt82B (for control clones) males were mated with $w$, elavGal4, hsFLP; tub-Gal80, Frt40A, w, elav-Gal4, hsFLP; tubGal80, Frt2A, or w, elav-Gal4, hsFLP; Frt82B, tub-Gal80 virgins. Embryos were collected for $2-3 \mathrm{~h}$ on grape agar plates at $25^{\circ} \mathrm{C}$ and were aged for an additional $2-3 \mathrm{~h}$ prior to heat-shock treatment. Embryos were heat-shocked for $40 \mathrm{~min}$ at $38^{\circ} \mathrm{C}$, followed by a room temperature recovery for $40 \mathrm{~min}$ and a second heat shock for $40 \mathrm{~min}$ at $38^{\circ} \mathrm{C}$. The collection plates were maintained at $25^{\circ} \mathrm{C}$, and first, second, or third instar larvae (as indicated) were examined for mutant clones and imaged directly or dissected, fixed, and stained with rat $\alpha$-CD8 antibody 1 1:200 dilution; Caltag).

\section{Immunocytochemistry}

Embryos were collected on grape agar plates, dechorionated in $50 \%$ bleach, and fixed in 50\% heptane/2\% EM-grade formaldehyde for $15 \mathrm{~min}$ with vigorous shaking. After removing the formaldehyde, embryos were devitellinized in 50\% heptane/ $50 \%$ methanol and washed extensively in methanol. Embryos were then washed four times in PBST (0.3\% Triton X-100), blocked in PBST $+5 \%$ normal donkey serum (NDS), and incubated overnight with primary antibodies diluted as follows in PBST/5\% NDS: FP3-38 ( $\alpha$-Ubx) 1:40, 6A8.12 ( $\alpha$-AbdA) 1:100, 1A2E9 ( $\alpha$-AbdB) 1:40, 8c11 ( $\alpha$-Antp) 1:40, 4c3 ( $\alpha$-Antp) 1:40, $\alpha$-B-gal 1:10,000, 22C10 1:100, BP102 1:10, and FasII 1:40. Cy2 or RRX-conjugated donkey secondary antibodies (Jackson Laboratories) were diluted 1:200 in NDS. To quantitate relative intensities from immunofluorescence, cells were manually outlined, and average pixel intensity was determined using $\mathrm{NIH}$ ImageJ.

\section{Immunoprecipitations}

S2 cells were transfected using the Effectine reagent (Qiagen). Two days after transfection, cells were lysed in Lysis buffer A (150 mM NaCl, 50 mM Tris- $\mathrm{HCl}$ at $\mathrm{pH}$ 7.4, 2 mM EDTA, 1\% Triton X-100, 10\% glycerol, $2 \mathrm{mM}$ dithiothreitol, $1 \mathrm{mM}$ benzamide, $1 \mathrm{mM}$ PMSF, $10 \mathrm{mM} \mathrm{NaF}, 20 \mathrm{mM} \beta$-glycerophosphate, 2 $\mathrm{mM}$ Na3VO4, and Complete protease inhibitor cocktail [Roche]) and spun at $5000 \mathrm{~g}$ for $15 \mathrm{~min}$. Extracts were precleaned by Protein G-Agarose beads (Roche) and then incubated with primary antibodies for $2 \mathrm{~h}$, followed by Protein G beads for $1 \mathrm{~h}$. Beads were washed five times in lysis buffer for analyses of associated proteins by SDS-PAGE and Western blotting.

\section{Acknowledgments}

We thank Juerg Muller, Richard Mann, Ian Duncan, Robert White, and Fabrice Roegiers for fly stocks and antibodies; the
Developmental Studies Hybridoma Bank for antibodies; the Bloomington stock center for fly stocks; Susan Younger and Michael Kim for experimental advice; and Tom Jessell for critical reading of the manuscript and helpful comments. This work was supported by a Ruth L. Kirschstein NRSA post-doctoral fellowship to J.Z.P. and NIH grant R01 NS40929 to Y.N.J. L.Y.J. and Y.N.J. are Investigators of the Howard Hughes Medical Institute.

\section{References}

Barnett, M.W., Seville, R.A., Nijiar, S., Old, R.W., and Jones, E.A. 2001. Xenopus Enhancer of Zeste (XEZ); an anteriorly restricted polycomb gene with a role in neural patterning. Mech. Dev. 102: 157-167.

Benavides-Piccione, R., Ballesteros-Yanez, I., de Lagran, M.M., Elston, G., Estivill, X., Fillat, C., Defelipe, J., and Dierssen, M. 2004. On dendrites in Down syndrome and DS murine models: A spiny way to learn. Prog. Neurobiol. 74: 111-126.

Bodmer, R. and Jan, Y.N. 1987. Morphological differentiation of the embryonic peripheral neurons in Drosophila. Rouxs Arch. Dev. Biol. 196: 69-77.

Boyer, L.A., Plath, K., Zeitlinger, J., Brambrink, T., Medeiros, L.A., Lee, T.I., Levine, S.S., Wernig, M., Tajonar, A., Ray, M.K., et al. 2006. Polycomb complexes repress developmental regulators in murine embryonic stem cells. Nature 441: 349-353.

Bracken, A.P., Dietrich, N., Pasini, D., Hansen, K.H., and Helin, K. 2006. Genome-wide mapping of Polycomb target genes unravels their roles in cell fate transitions. Genes \& Dev. 20: 1123-1136.

Brenman, J.E., Gao, F.B., Jan, L.Y., and Jan, Y.N. 2001. Sequoia, a tramtrack-related zinc finger protein, functions as a panneural regulator for dendrite and axon morphogenesis in Drosophila. Dev. Cell. 1: 667-677.

Cao, R., Wang, L., Wang, H., Xia, L., Erdjument-Bromage, H., Tempst, P., Jones, R.S., and Zhang, Y. 2002. Role of histone H3 lysine 27 methylation in Polycomb-group silencing. Science 298: 1039-1043.

Czermin, B., Melfi, R., McCabe, D., Seitz, V., Imhof, A., and Pirrotta, V. 2002. Drosophila enhancer of Zeste/ESC complexes have a histone $\mathrm{H} 3$ methyltransferase activity that marks chromosomal Polycomb sites. Cell 111: 185-196.

Dasen, J.S., Tice, B.C., Brenner-Morton, S., and Jessell, T.M. 2005. A Hox regulatory network establishes motor neuron pool identity and target-muscle connectivity. Cell 123: $477-$ 491.

Emoto, K., He, Y., Ye, B., Grueber, W.B., Adler, P.N., Jan, L.Y., and Jan, Y.N. 2004. Control of dendritic branching and tiling by the Tricornered-kinase/Furry signaling pathway in Drosophila sensory neurons. Cell 119: 245-256.

Emoto, K., Parrish, J.Z., Jan, L.Y., and Jan, Y.N. 2006. The tumour suppressor Hippo acts with the NDR kinases in dendritic tiling and maintenance. Nature 443: 210-213.

Grueber, W.B. and Jan, Y.N. 2004. Dendritic development: Lessons from Drosophila and related branches. Curr. Opin. Neurobiol. 14: 74-82.

Grueber, W.B., Jan, L.Y., and Jan, Y.N. 2002. Tiling of the Drosophila epidermis by multidendritic sensory neurons. Development 129: 2867-2878.

Grueber, W.B., Jan, L.Y., and Jan, Y.N. 2003a. Different levels of the homeodomain protein cut regulate distinct dendrite branching patterns of Drosophila multidendritic neurons. Cell 112: 805-818.

Grueber, W.B., Ye, B., Moore, A.W., Jan, L.Y., and Jan, Y.N. 
2003b. Dendrites of distinct classes of Drosophila sensory neurons show different capacities for homotypic repulsion. Curr. Biol. 13: 618-626.

Grueber, W.B., Ye, B., Yang, C.H., Younger, S., Borden, K., Jan, L.Y., and Jan, Y.N. 2007. Projections of Drosophila multidendritic neurons in the central nervous system: Links with peripheral dendrite morphology. Development 134: 5564.

Huang, J., Wu, S., Barrera, J., Matthews, K., and Pan, D. 2005. The Hippo signaling pathway coordinately regulates cell proliferation and apoptosis by inactivating Yorkie, the Drosophila homolog of YAP. Cell 122: 421-434.

Jones, C.A., Ng, J., Peterson, A.J., Morgan, K., Simon, J., and Jones, R.S. 1998. The Drosophila esc and E(z) proteins are direct partners in Polycomb group-mediated repression. Mol. Cell. Biol. 18: 2825-2834.

Jungbluth, S., Bell, E., and Lumsden, A. 1999. Specification of distinct motor neuron identities by the singular activities of individual Hox genes. Development 126: 2751-2758.

Kaufmann, W.E. and Moser, H.W. 2000. Dendritic anomalies in disorders associated with mental retardation. Cereb. Cortex 10: 981-991.

Kitaguchi, T., Nakata, K., Nagai, T., Aruga, J., and Mikoshiba, K. 2001. Xenopus Polycomblike 2 (XPcl2) controls anterior to posterior patterning of the neural tissue. Dev. Genes Evol. 211: 309-314.

Klymenko, T., Papp, B., Fischle, W., Kocker, T., Schelder, M., Fritsch, C., Wild, B., Wilm, M., and Muller, J. 2006. A Polycomb group protein complex with sequence-specific DNAbinding and selective methyl-lysine-binding activities. Genes \& Dev. 20: 1110-1122.

Kwon, H.J. and Chung, H.M. 2003. Yin Yang 1, a vertebrate polycomb group gene, regulates antero-posterior neural patterning. Biochem. Biophys. Res. Commun. 306: 1008-1013.

Lee, T. and Luo, L. 2001. Mosaic analysis with a repressible cell marker for studies of gene function in neuronal morphogenesis. Neuron 22: 451-461.

Lee, A., Li, W., Xu, K., Bogert, B.A., Su, K., and Gao, F.B. 2003. Control of dendritic development by the Drosophila fragile $\mathrm{X}$-related gene involves the small GTPase Rac1. Development 130: 5543-5552.

Lee, N., Maurange, C., Ringrose, L., and Paro, R. 2006. Suppression of Polycomb group proteins by JNK signalling induces transdetermination in Drosophila imaginal discs. Nature 438: 234-237.

Li, W., Wang, F., Menut, L., and Gao, F.B. 2004. BTB/POZ-zinc finger protein abrupt suppresses dendritic branching in a neuronal subtype-specific and dosage-dependent manner. Neuron 43: 823-834.

Liu, J.P., Laufer, E., and Jessell, T.M. 2001. Assigning the positional identity of spinal motor neurons: Rostrocaudal patterning of Hox-c expression by FGFs, Gdf11, and retinoids. Neuron 32: 997-1012.

Lund, A.H. and van Lohuizen, M. 2004. Polycomb complexes and silencing mechanisms. Curr. Opin. Cell Biol. 16: 239246.

Merritt, D.J. and Whitington, P.M. 1995. Central projections of sensory neurons in the Drosophila embryo correlate with sensory modality, soma position, and proneural gene function. J. Neurosci. 15: 1755-1767.

Merritt, D.J. and Whitington, P.M. 2002. Homeotic genes influence the axonal pathway of a Drosophila embryonic sensory neuron. Int. J. Dev. Biol. 46: 633-638.

Miguel-Aliaga, I. and Thor, S. 2004. Segment-specific prevention of pioneer neuron apoptosis by cell-autonomous, postmitotic Hox gene activity. Development 131: 6093-6105.
Muller, J., Hart, C.M., Francis, N.J., Vargas, M.L., Sengupta, A., Wild, B., Miller, E.L., O'Connor, M.B., Kingston, R.E., and Simon, J.A. 2002. Histone methyltransferase activity of a Drosophila Polycomb group repressor complex. Cell 111: 197-208.

Ng, J., Hart, C.M., Morgan, K., and Simon, J.A. 2000. A Drosophila ESC-E(Z) protein complex is distinct from other polycomb group complexes and contains covalently modified ESC. Mol. Cell. Biol. 20: 3069-3078.

Parrish, J.Z., Kim, M.K., Jan, L.Y., and Jan, Y.N. 2006. Genomewide analyses identify transcription factors required for proper morphogenesis of Drosophila sensory neuron dendrites. Genes \& Dev. 20: 820-835.

Ringrose, L. and Paro, R. 2004. Epigenetic regulation of cellular memory by the Polycomb and Trithorax group proteins. Annu. Rev. Genet. 38: 413-443.

Rockhill, R.L., Daly, F.J., MacNeil, M.A., Brown, S.P., and Masland, R.H. 2002. The diversity of ganglion cells in a mammalian retina. J. Neurosci. 22: 3831-3843.

Saurin, A.J., Shao, Z., Erdjument-Bromage, H., Tempst, P., and Kingston, R.E. 2001. A Drosophila Polycomb group complex includes Zeste and dTAFII proteins. Nature 412: 655-660.

Schrader, S. and Merritt, D.J. 2000. Central projections of Drosophila sensory neurons in the transition from embryo to larva. J. Comp. Neurol. 425: 34-44.

Schwartz, Y.B., Kahn, T.G., Nix, D.A., Li, X.Y., Bourgon, R., Biggin, M., and Pirrotta, V. 2006. Genome-wide analysis of Polycomb targets in Drosophila melanogaster. Nat. Genet. 38: 700-705.

Shindo, N., Sakai, A., Arai, D., Matsuoka, O., Yamasaki, Y., and Higashinakagawa, T. 2005. The ESC-E(Z) complex participates in the hedgehog signaling pathway. Biochem. Biophys. Res. Commun. 327: 1179-1187.

Simon, J., Chiang, A., and Bender, W. 1992. Ten different Polycomb group genes are required for spatial control of the $a b d A$ and $A b d B$ homeotic products. Development 114: 493 505.

Simon, J., Chiang, A., Bender, W., Shimell, M.J., and O'Connor, M. 1993. Elements of the Drosophila bithorax complex that mediate repression by Polycomb group products. Dev. Biol. 158: 131-144.

Struhl, G. 1983. Role of the $\operatorname{esc}^{+}$gene product in ensuring the selective expression of segment-specific homeotic genes in Drosophila. J. Embryol. Exp. Morphol. 76: 297-331.

Su, I.H., Dobenecker, M.W., Dickinson, E., Oser, M., Basavaraj, A., Marqueron, R., Viale, A., Reinberg, D., Wulfing, C., and Tarakhovsky, A. 2005. Polycomb group protein ezh2 controls actin polymerization and cell signaling. Cell 121: 425436.

Sugimura, K., Yamamoto, M., Niwa, R., Satoh, D., Goto, S., Taniguchi, M., Hayashi, S., and Uemura, T. 2003. Distinct developmental modes and lesion-induced reactions of dendrites of two classes of Drosophila sensory neurons. J. Neurosci. 23: 3752-3760.

Sugimura, K., Satoh, D., Estes, P., Crews, S., and Uemura, T. 2004. Development of morphological diversity of dendrites in Drosophila by the BTB-zinc finger protein abrupt. Neuron 43: 809-822.

Tie, F., Furuyama, T., Prasad-Sinha, J., Jane, E., and Harte, P.J. 2001. The Drosophila Polycomb Group proteins ESC and $\mathrm{E}(\mathrm{Z})$ are present in a complex containing the histone-binding protein $\mathrm{p} 55$ and the histone deacetylase RPD3. Development 128: $275-286$.

Tolhuis, B., de Wit, E., Muijrers, I., Teunissen, H., Talhout, W., van Steensel, B., and van Lohuizen, M. 2006. Genome-wide profiling of PRC1 and PRC2 Polycomb chromatin binding in 
Parrish et al.

Drosophila melanogaster. Nat. Genet. 38: 694-699.

Wang, J., Lee, C.H., Lin, S., and Lee, T. 2006. Steroid hormonedependent transformation of polyhomeotic mutant neurons in the Drosophila brain. Development 133: 1231-1240.

Wassle, H., Peichl, L., and Boycott, B.B. 1978. Topography of horizontal cells in the retina of the domestic cat. Proc. $R$. Soc. Lond. B. Biol. Sci. 203: 269-291.

Wassle, H., Peichl, L., and Boycott, B.B. 1983. Mosaics and territories of cat retinal ganglion cells. Prog. Brain Res. 58: 183 190.

Ye, B., Petritsch, C., Clark, I.E., Gavis, E.R., Jan, L.Y., and Jan, Y.N. 2004. Nanos and Pumilio are essential for dendrite morphogenesis in Drosophila peripheral neurons. Curr. Biol. 14: 314-321. 


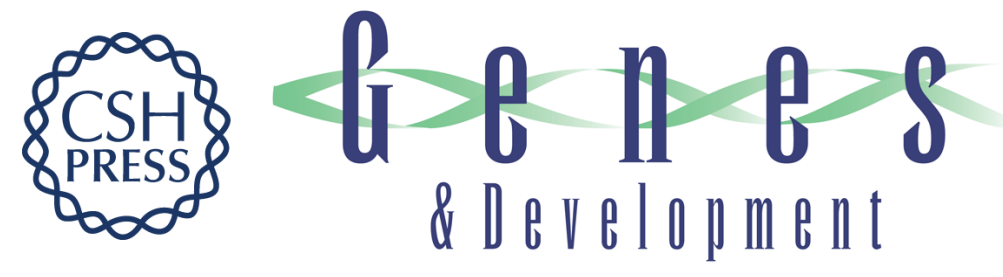

\section{Polycomb genes interact with the tumor suppressor genes hippo and warts in the maintenance of Drosophila sensory neuron dendrites}

Jay Z. Parrish, Kazuo Emoto, Lily Yeh Jan, et al.

Genes Dev. 2007, 21:

Access the most recent version at doi:10.1101/gad.1514507

Supplemental http://genesdev.cshlp.org/content/suppl/2007/05/01/21.8.956.DC1
Material

References This article cites 53 articles, 16 of which can be accessed free at: http://genesdev.cshlp.org/content/21/8/956.full.html\#ref-list-1

License Freely available online through the Genes \& Development Open Access option.

Email Alerting Receive free email alerts when new articles cite this article - sign up in the box at the top Service right corner of the article or click here.

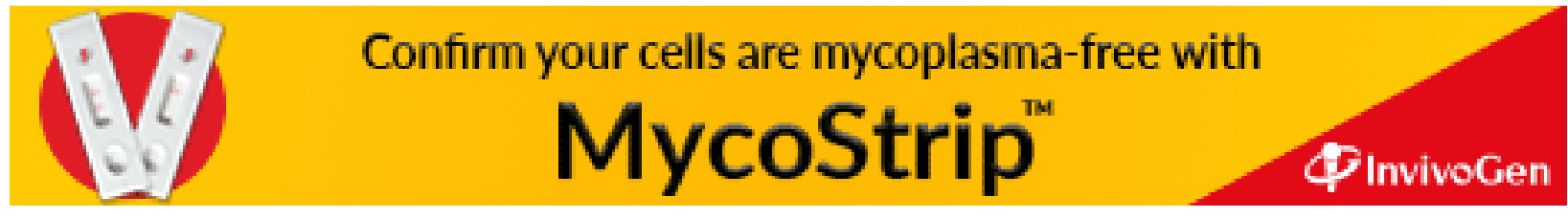

